DIW BERLIN

Discussion

Papers

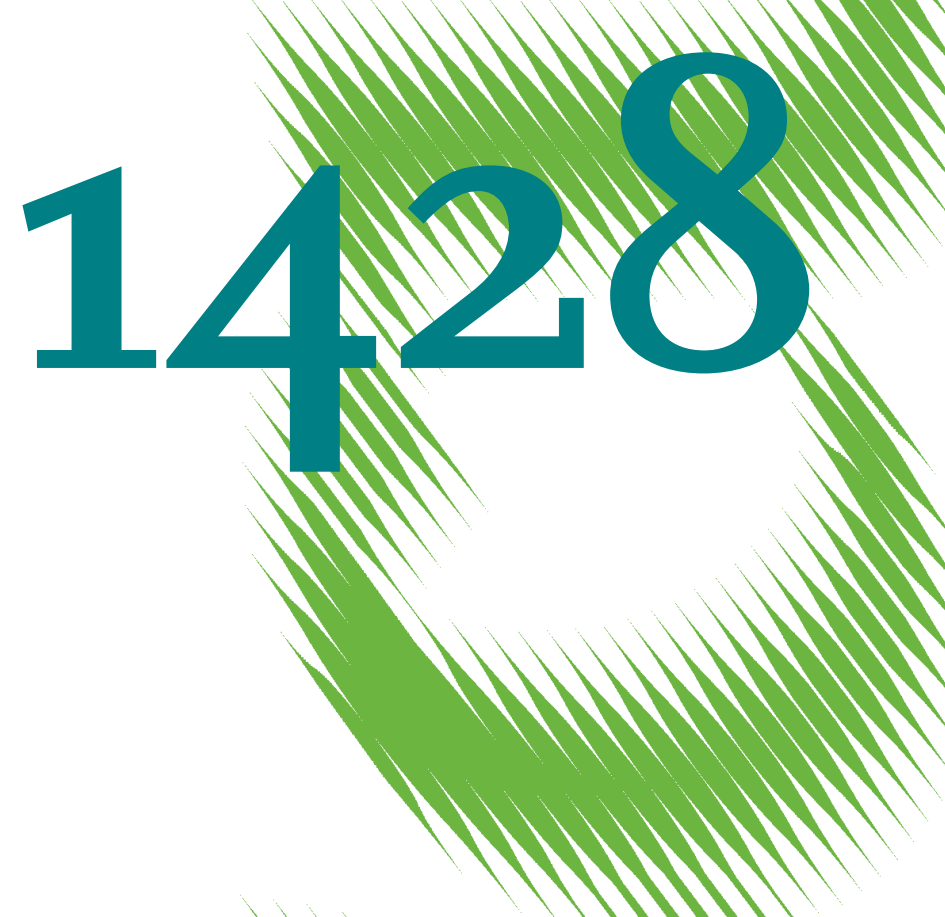

How Does Fuel Taxation

Impact New Car Purchases?

An Evaluation Using French

Consumer-Level Data 
Opinions expressed in this paper are those of the author(s) and do not necessarily reflect views of the institute.

IMPRESSUM

(C) DIW Berlin, 2014

DIW Berlin

German Institute for Economic Research

Mohrenstr. 58

10117 Berlin

Tel. +49 (30) $89789-0$

Fax +49 (30) $89789-200$

http://www.diw.de

ISSN electronic edition 1619-4535

Papers can be downloaded free of charge from the DIW Berlin website:

http://www.diw.de/discussionpapers

Discussion Papers of DIW Berlin are indexed in RePEc and SSRN:

http://ideas.repec.org/s/diw/diwwpp.html

http://www.ssrn.com/link/DIW-Berlin-German-Inst-Econ-Res.html 


\title{
How does fuel taxation impact new car purchases? An evaluation using French consumer-level data*
}

\author{
Pauline Givord ${ }^{\dagger} \quad$ Céline Grislain-Letrémy ${ }^{\ddagger} \quad$ Helene Naegele ${ }^{\S}$
}

November 29, 2014

\begin{abstract}
This study evaluates the impact of fuel prices on new automobile purchases, using exhaustive individual-level data of monthly registration of new cars in France from 2003 to 2007. Detailed information on the car holder enables us to account for heterogeneous preferences across purchasers. We identify demand parameters through the large oil price fluctuations of this period. We find that the sensitivity of shortterm demand with respect to fuel prices is generally low. Using these estimates, we assess the impact of a policy equalizing diesel and gasoline taxes. Such a policy would reduce the share of diesel in new cars purchases from $69 \%$ to $66 \%$ in the short-run, without substantially changing the average fuel consumption or $\mathrm{CO}_{2}$ emission levels of new cars. Alternatively, a carbon tax would slightly decrease the $\mathrm{CO}_{2}$ emission levels of new cars in the short-run (by $0.1 \%$ ) without any significant impact on the share of diesel cars purchased.
\end{abstract}

JEL : C25, D12, H23, L62, Q53.

Keywords : fuel prices, automobiles, carbon dioxide emissions, environmental $\operatorname{tax}$.

*The authors thank Xavier D'Haultfœuille, Éric Dubois, Emmanuel Massé, Corinne Prost and Hannes Ullrich for their insightful comments. This paper has benefited from comments by participants at the 12th Louis-André Gerard-Varet seminar, the INSEE internal seminar, the fifth World Congress of Environmental and Resource Economists, the 41th annual conference of the European Association for Research in Industrial Economics, and the 29th annual congress of the European Economic Association. The authors also thank Julien Mollet and Pierre-Louis Debar (both CCFA, Comité des Constructeurs Français d'Automobiles) for providing us with the data.

${ }^{\dagger}$ INSEE. pauline.givord at insee.fr

${ }^{\ddagger}$ INSEE (CREST) and University Paris-Dauphine. celine.grislain.letremy at ensae.fr

${ }^{\S}$ DIW. HNaegele at diw.de 


\section{Introduction}

With increasing concerns about global warming, a variety of policies are under consideration to reduce $\mathrm{CO}_{2}$ emissions from road transport. The main measures are fuel taxes, emission standards, feebates, and innovation subsidies. In theory, fuel taxes present the advantage that they affect both the present and future of road transport emissions: car owners are immediately incited to drive less with their current car when fuel prices rise, while at the same time purchasing fuel-efficient cars becomes more attractive (see Austin \& Dinan (2005) for a more extensive comparison). The composition of the vehicle fleet could be durably changed, so that lock-in effects would guarantee future fuel savings. In France, road transport produces more than a third of total $\mathrm{CO}_{2}$ emissions and much higher shares of other greenhouse gases.1 However, previous results, based on the US market, emphasize an "energy paradox", namely the fact that consumers systematically undervalue future economies of energy-efficiency (e.g. Allcott \& Wozny, 2014).

This paper analyzes the impact of fuel price variations, and more specifically those due to changes in fuel taxes, on the structure of demand for new vehicles in France. We use our estimates to examine two policy alternatives: a "carbon tax" and the equalization of diesel and gasoline taxes.

In 2013, France passed a "carbon tax" that levies a tax based upon the $\mathrm{CO}_{2}$ content of the fuel. This tax explicitly aims at reflecting the externality cost to society, i.e. it is proportional to the amount of carbon emitted. However, the actual effectiveness of this new tax depends upon car purchasers' sensitivity to fuel efficiency and fuel prices. As a first result, we provide an ex ante estimation of the French carbon tax impact on the structure of car purchases, especially with regard to fuel efficiency and emission intensities.

Especially in Europe, fuel is one of the most heavily taxed goods; with selling prices comprising up to $75 \%$ of taxes, as in France in 2003. Moreover, diesel and gasoline are taxed at different rates: after the 1970s era oil crisis, the French government decided to support fuel-efficient diesel cars by reducing taxes on diesel fuels relative to gasoline taxes. In 2011 the consumption tax on energy products reached $€ 0.61$ per liter of gasoline, while it amounted to $€ 0.44$ per liter of diesel. As shown by Hivert (2013), the advantage given to diesel cars in France is particularly salient in an international comparison.

This tax advantage for diesel is subject to ongoing debate. Like many others, Cames \& Helmers (2013) argue that environmental benefits of diesel cars are overestimated: new technology decreases the spread between $\mathrm{CO}_{2}$-emission-efficiency of diesel and gasoline cars, but diesel cars continue to produce other greenhouse gases (NOx, ozone, black carbon) and medically hazardous particulate matter..$^{2}$ In this context, Miravete et al. (2014)

\footnotetext{
${ }^{1}$ http://www.citepa.org/en/air-and-climate/analysis-by-sector/transports

${ }^{2}$ Since 2011, diesel particulate filters are mandatory for new vehicles in France (see Massé (2005) for a
} 
go as far as to argue that diesel-friendly policy in Europe is essentially a non-tariff trade barrier against American manufacturers. The production of diesel-models is also more $\mathrm{CO}_{2}$ intensive because they are heavier. Against this background, the French government is considering the abolition of the relative advantages for diesel fuel; the (hypothetical) second policy under investigation in this study.

We use French car registration data from 2003 to 2007, which includes exhaustive information about both households' and firms' automobile purchases. Our main focus lies on the aggregate impact of fuel taxes on fuel efficiency, emission levels and the share of diesel purchases. However, in order to correctly account for the heterogeneity of purchasers, we differentiate between purchaser types. Our dataset allows for such a precise distinction, as it links technical car characteristics to information on the car holder, including age, activity status, and residential area for private consumers, and business sector and location for firms. This is a decisive advantage that enables us to define types of purchasers to account for observed heterogeneity in preferences across purchasers. In particular, we can separate between private consumers and firms. While the latter represent a large share of purchases of new cars (more than one-third over the period) in France, limited evidence exists so far on their responsiveness to changes in fuel prices.

As it is common in this literature, we rely on a static discrete choice model assuming that the decision to buy a specific car is related to a valuation of several car characteristics, including the cost per kilometer. More specifically, we rely on a nested logit that enables us to account for taste correlation within car market segments and between fuel-type versions of the same model. Over the studied period, fuel prices vary considerably. We identify the impact of fuel cost in car choice using time variation in fuel prices and cross-sectional differences in cars' fuel efficiency. We estimate the elasticity of demand for cars with respect to an increase of oil prices (i.e. prices of all fuel-types exclusive of tax) and with respect to fuel taxes.

Our results suggest that short-term sensitivity of demand with respect to fuel prices is generally low, but presents significant heterogeneity across purchasers. The difference between private and firm purchases is particularly salient: firms are much less sensitive to fuel price changes than households. Altogether, our estimated elasticities suggest that such a policy would reduce the market share of diesel cars (from $69 \%$ to $66 \%$ ) without notably changing average fuel efficiency or $\mathrm{CO}_{2}$ emission level $3^{3}$. The short-term impact of the carbon tax would be even more modest on these outcomes.

This paper is in line with a burgeoning literature on the impact of fuel prices on automobile sector. Most papers focus on American data (Allcott \& Wozny, 2014, Busse et al., 2013,

complete analysis).

${ }^{3}$ In all our study, we assume that consumers react to changes in fuel prices indifferently to whether they are due to a rise in fuel taxes or due to a rise in oil prices. 
Klier \& Linn, 2010). Klier \& Linn (2013), who evaluate the effect of fuel prices on new vehicle fuel economy in the eight largest European markets (including France), observe strong differences between European and American markets. Most of this existing literature is based on data with little or no information on consumers. Data, as used in this article, that are exhaustive and contain detailed information on both cars and purchasers, are rare. Indeed, our data allow us to observe purchaser heterogeneity: apart from the distinction between firms and private consumers, we split the sample according to several dimensions that may matter in the sensitivity to fuel prices. Previous results for France suggest that the elasticity of fuel demand to fuel prices in France is heterogeneous across demographic groups (Clerc \& Marcus, 2009), depending notably on working status. Using French data as well, Calvet \& Marical (2011) argue that the impact of such taxes on the overall fuel consumption is low in the short term, because utilization is inelastic and the impact thus mostly passes through the renewal of the car-fleet (which is the focus of this article).

The paper is organized as follows. Section 2 explains our assumptions on the decision making process. Section 3 presents the data and some descriptive statistics. The model is presented in Section 4. Section 5 exposes results and robustness tests, and Section 7 concludes.

\section{Choice model}

To model market shares of new vehicles, we rely on a standard discrete choice model with differentiated products. More specifically, we assume that the purchaser buys one product that maximizes a linear utility, taking into account the characteristics of the available new vehicles. The individual valuation of these vehicles may vary among individuals (like e.g. Allcott \& Wozny, 2014, tracing back to seminal work by McFadden, 1978).

We assume that consumers take a sequential decision, choosing first a car segment (i.e. SUV, compact, etc; see list in Table 1), then a model (combination of nameplate and car body style) within that segment and finally one of the two fuel-type versions of that model ${ }^{4}$. This yields heterogeneous substitution patterns between products that are more or less similar. We rely on a nested logit specification with two nesting levels to account for this correlation structure. First, we assume that the individual unobserved preferences are correlated between a set of defined car segments. This specification makes e.g. a sporty BMW Z3 more substitutable to a BMW Z4 than to a bulky Citroen Berlingo. In addition, we assume that a model combines a set of unobserved characteristics valued by the

\footnotetext{
4"Nameplate" refers to the brand name of the car, e.g. Corolla, Prius. Within the same nameplate, there are usually several "models" which are defined in this study by the intersection of a nameplate and a body style, i.e. Corolla sedan or Corolla station wagon. Each model usually exists in a diesel- and a gasoline-version.
} 
consumer regardless of the engine type (gasoline or diesel). Thus, the preferences for the gasoline and diesel versions of the same nameplate series are expected to be correlated. We also consider an outside option, which is not to buy any new vehicle $5^{5}$ This substitution pattern is represented in the tree diagram of Fig. 1 .

The individual utility of choosing the product of model (combination of nameplate and car body style) $j$, fuel-type $f$ and segment $s$, for purchaser $i$ at month $t$ is written:

$$
u_{i j f t}=\alpha+\beta p_{j f t}^{k m}+\gamma_{1} p_{j f t}+\gamma_{2} X_{j f t}+\xi_{j f t}+\epsilon_{i j f t},
$$

where $p_{j f t}$ denotes the car price and $X_{j f t}$ represents the characteristics of new cars, namely horsepower, $\mathrm{CO}_{2}$ class, number of doors, fuel-type, car body (sedan, sport, compact, etc.) and brand. $p_{j f t}^{k m}$ is the cost at time $t$ for the amount of fuel needed to drive one $\mathrm{km}$ with the model $j$ of fuel-type $f{ }^{6} \xi_{i j f t}$ measures the unobserved (to the econometrician) preference for product $j f$. As such, it captures attributes like perceived quality, reliability and reputation.

To reflect our decision process of Fig. 1, we allow for a specific correlation structure between the unobserved idiosyncratic preferences for products of the same segment and for fuel-versions of the same model. We assume that the error term may be decomposed as:

$$
\epsilon_{i j f t}=\nu_{i s t}+\left(1-\sigma_{2}\right)\left(\nu_{i j t}+\left(1-\sigma_{1}\right) e_{i j f t}\right),
$$

where $\nu_{i j t}$ measures the preference for unobserved characteristics of model $j$ common to both fuel versions, for example design, while $\nu_{i s t}$ is common to all cars in the segment $s$, for example status symbol value. The remaining error $e_{i j f t}$ is assumed to be independent and identically distributed according to an extreme value distribution. It can be shown that we can find a unique distribution for $\nu_{i s t}$ and $\nu_{i j t}$ such that $\epsilon_{i j f t}$ follows an extreme value distribution (Cardell, 1997). This specification is standard in this literature (see in particular Berry, 1994).

The parameters $\sigma_{1}$ and $\sigma_{2}$ capture the correlation between individual preferences for cars within nests, as defined above. As shown by McFadden (1978), the nested logit model is consistent with random-utility maximization for values of $\sigma_{1}$ and $\sigma_{2}$ between 0 and 1 . $\sigma_{1}=0$ means that substitution effects are identical across and within model. 7 while a high

\footnotetext{
${ }^{5}$ As we consider monthly sales, the outside option's market share is likely to be much larger than any other option's share. For the sake of comparison, over the period the number of new cars registered a month ranges from 75,000 to 160,000 vehicles, for around 37.5 millions of drivers in France.

${ }^{6}$ Another way to look at this would be to multiply the fuel consumption by the number of kilometers expected by the purchaser and using some sort of discounting; this is equivalent to our presentation if $\beta_{i}$ is simply defined to include this expected number of kilometers and discount factor of purchaser $i$.

7"Within-model" substitution means for example a substitution between the gasoline-powered and the diesel-powered cars of the same model.
} 
Figure 1: Decision-making process of the car purchaser

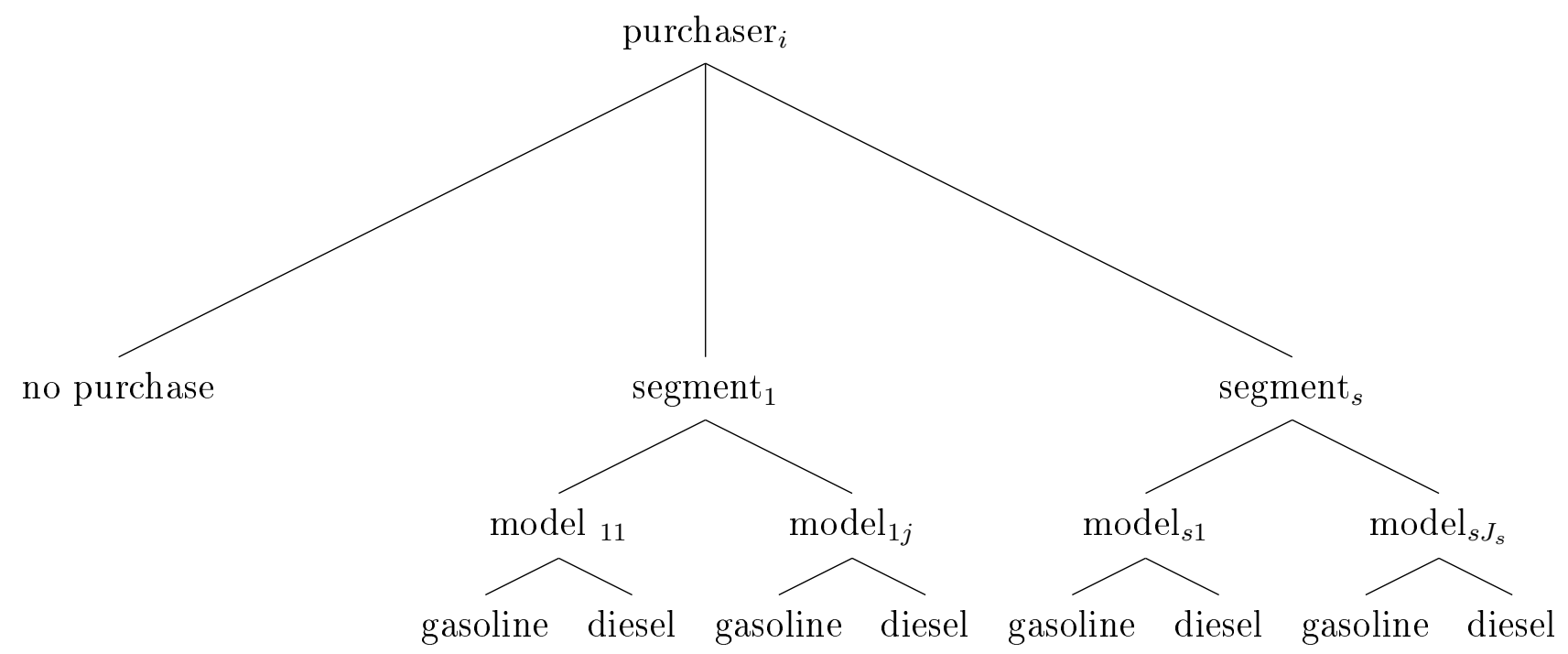

$\sigma_{1}$ (tending to 1) implies a high correlation between preferences for both fuel-versions of the same model. $\sigma_{2}=0$ implies that the purchaser is a priori indifferent to substitute between models within and across segments (see for example Verboven (1996) for a more complete discussion of these terms).

The taste for characteristics and unobserved preferences for differentiated products or the outside good might be different across heterogeneous individuals. For example, individual valuation by a purchaser of the price per kilometer depends on their expected traveled kilometers, which may vary depending on working status or area of living. Not accounting for such heterogeneity may result in biased estimates. 8 In the following we will thus define groups of consumers based on observable characteristics and estimate preferences for each group separately.

\footnotetext{
${ }^{8}$ To illustrate this, let us assume that we have heterogeneity by group of purchasers. Using aggregate market shares, one would model $\ln \left(\sum_{d}\left(q_{d}\right)\right)$, where $q_{d}$ is the quantity bought by group $d$ of purchasers. If the real model is such that we have $\ln \left(q_{d}\right) \propto \beta_{d} \phi p_{f}$ for all groups of purchasers, the linear model for aggregated market share would be misspecified as the ln function is not a linear operator (and thus $\left.\ln \left(\sum_{d}\left(q_{d}\right)\right) \neq \sum_{d}\left(\ln \left(q_{d}\right)\right)\right)$.
} 


\section{Data}

\subsection{New vehicle registrations}

We use the exhaustive dataset of all new cars registered in France from January 2003 to November 2007, provided by the Association of French Automobile Manufacturers (CCFA, Comité des Constructeurs Français d'Automobiles), giving us over 7 million observed registrations. As a feebate scheme dramatically changed the demand for fuel economy starting in November 2007, we only use data up to that date (see D'Haultfœuille et al. (2014) for an analysis of this policy and a description of this dataset). It includes all information necessary for the registration of a new car, i.e. both technical specifications of the car as well as linked information on the purchaser. We split the sample into demographic groups based on purchaser characteristics and use a detailed definition of a product. The dataset also contains the list prices (not necessarily the actual selling prices) of new cars, as provided by car manufacturers.

The data set contains some technical characteristics of the car: brand, nameplate, $\mathrm{CO}_{2}$ emission class, type of fuel, number of doors, type of car-body, horsepower, weight and cylinder capacity. This information allows us to define the products at a detailed level. Purchasers face a discrete choice between different products, which are defined by a set of characteristics. The definition should be fine enough to avoid the aggregation of heterogeneous products. At the same time, a too narrow definition yields many zero (monthly) market shares. Trading off between these two effects, we define a product by the intersection of brand, nameplate, fuel-type (diesel or gasoline).$^{9}$ and body style (e.g. city-car and sedan) $1^{10}$ Given the outlined structure of the decision process, we exclude nameplates that are available with only one fuel-type (diesel or gasoline); this is only the case for rather exceptional cars which represent $22 \%$ of the nameplates but only $7 \%$ of sales.

Importantly, our administrative registration data match every sale of a new car with information on the new car owner. We can distinguish between private individuals and firms. For the former, we observe the municipality they live in (postal code), their age and activity status (working or not). For the latter, we have information on the location and the business sector. It is a considerable advantage to take into account the heterogeneity in taste of customers for differentiated products. Fuel price elasticities are likely to be related to consumer characteristics such as income, working status and area of residence. Most of the relevant literature on fuel elasticity does not rely on such an individual matching, but as noted by Bento et al. (2012), this omission might entail erroneous findings about fuel economy valuation.

\footnotetext{
${ }^{9}$ We exclude electric and hybrid vehicles as they constitute a tiny share of the French market over the examined period.

${ }^{10}$ This definition is similar to Allcott \& Wozny (2014) and somewhat more detailed than those used in most of the literature (e.g. Goldberg (1995) and Verboven (1996))
} 
Table 1: Descriptive statistics of cars

\begin{tabular}{|c|c|c|c|c|c|}
\hline & Products & Sales-weighted & & Products & Sales-weighted \\
\hline \multicolumn{3}{|c|}{ By type of car-body } & \multicolumn{3}{|c|}{ By class of $\mathrm{CO}_{2}(\mathrm{~g} / \mathrm{km})$} \\
\hline City-car & $3 \%$ & $7 \%$ & $\leq 100$ & 0 & 0 \\
\hline Sedan & $33 \%$ & $27 \%$ & 101 to 120 & $4 \%$ & $16 \%$ \\
\hline Compact & $14 \%$ & $32 \%$ & 121 to 140 & $9 \%$ & $24 \%$ \\
\hline Sport & $20 \%$ & $4 \%$ & 141 to 160 & $14 \%$ & $31 \%$ \\
\hline Minivan & $13 \%$ & $21 \%$ & 161 to 200 & $29 \%$ & $20 \%$ \\
\hline All-road/SUV & $10 \%$ & $6 \%$ & 201 to 250 & $26 \%$ & $6 \%$ \\
\hline Utilitarian & $6 \%$ & $4 \%$ & $>250$ & $18 \%$ & $2 \%$ \\
\hline \multicolumn{3}{|l|}{ By horsepower } & \multicolumn{3}{|l|}{ By type of fuel } \\
\hline$\leq 60$ & $14 \%$ & $31 \%$ & Gasoline & $58 \%$ & $31 \%$ \\
\hline 61 to 100 & $35 \%$ & $56 \%$ & Diesel & $42 \%$ & $69 \%$ \\
\hline 101 to 140 & $27 \%$ & $10 \%$ & & & \\
\hline 141 to 180 & $13 \%$ & $2 \%$ & & & \\
\hline$>180$ & $10 \%$ & $1 \%$ & & & \\
\hline \multicolumn{4}{|c|}{ Number of products and observations } & 2,160 & $7,405,367$ \\
\hline
\end{tabular}

Source: CCFA, authors' calculations.

\subsection{Diesel and gasoline cars}

As shown by Hivert (2013), the advantage given to diesel cars in France is particularly salient in international comparison. Figure 2 illustrates this specific position of France among European countries. Outside Europe, policies are even less favorable and dieselengines virtually do not exist: in both in Japan and the US, diesel cars make up about $2 \%$ of the overall car fleet (Cames \& Helmers, 2013).

Within the time frame of the data used in this study, from January 2003 through November 2007, gasoline and diesel prices became more variable, with a general upward trend, after some time of relative stability (Figure 3). Fuel prices varied considerably between $€ 1.01$ per liter and $€ 1.38$ per liter of gasoline, and between $€ 0.75$ and $€ 1.21$ per liter of diesel $\leftarrow^{11}$

\footnotetext{
${ }^{11}$ Monthly fuel prices are obtained from the French Ministry of Environment; we use sales-weighted national average prices available at http://www.developpement-durable.gouv.fr/ Prix-de-vente-moyens-des, 10724.html. For diesel prices we use the price of car diesel oil ("gazole"), while for gasoline price we use premium unleaded gasoline ("super sans plomb 95"). All price indications in this paper are deflated by the French National Statistical Institute (INSEE) consumer price index, taking January 2008 as reference.
} 


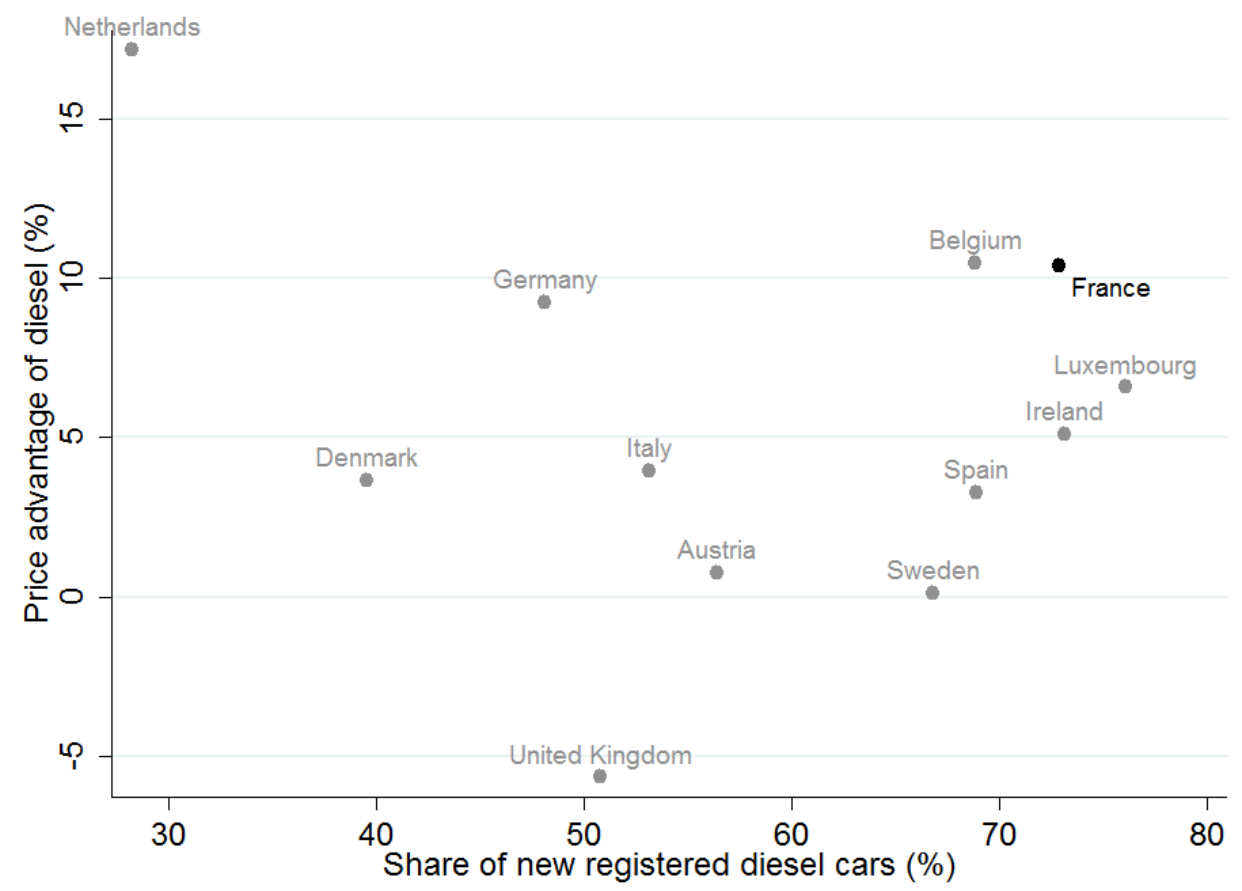

Figure 2: Diesel fuel prices and market shares in Europe in 2012

Source: European Automobile Manufacturer's Association (ACEA). Price advantage of diesel is defined as the price differential (including taxes) between diesel and super unleaded gasoline (95 RON) divided by the latter.

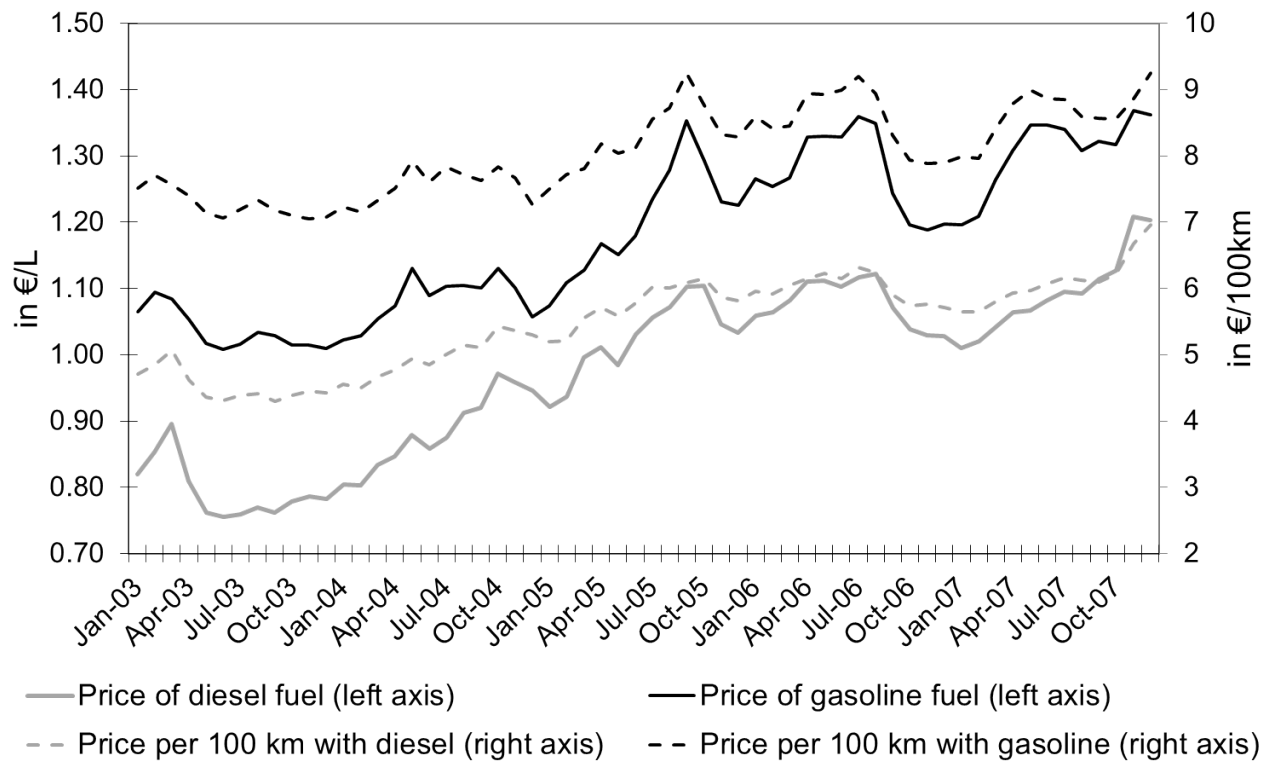

Figure 3: Monthly fuel prices and cost per km (resulting from fuel prices and average purchased fuel consumption)

Source: French Ministry of Ecology and CCFA, authors' calculations. 
However, over the whole examined period, diesel fuel prices are significantly lower than gasoline prices (Figure 3) because of the lower tax on diesel fuel. Indeed, fuel tax is a main component of French fuel prices. The final fuel tax rates result from the combination of a lump sum $\operatorname{tax}^{12}$ and the proportional VAT of $19.6 \%$. From an accounting perspective, the fuel price can be decomposed as:

$$
p_{f}=\left(1+t^{V A T}\right)\left[p^{e}+\mathbb{1}_{f=\text { diesel }}\left(t_{D}\right)+\mathbb{1}_{f=\text { gas }}\left(t_{G}\right)\right]
$$

where $t_{D}$ and $t_{G}$ are the consumption lump-sum taxes for one liter of diesel and gasoline, respectively, and $t^{V A T}$ the VAT rate. Pre-tax prices for gasoline and diesel are highly correlated (correlation over 0.95) and their difference is rather small (between -3 and 9 cents). Although pre-tax diesel prices are, on average, slightly higher than pre-tax gasoline (3 cents higher), we assume that price variations of both depend equally on oil prices, denoted $p^{e}$.

Over our study period the tax share exceeds $60 \%$ of the end-user price for gasoline and $50 \%$ for diesel. The tax rates on diesel are clearly advantageous relative to gasoline tax rates.

Additionally, diesel engines are more efficient than gasoline ones: they consume significantly fewer liters of fuel to drive the same distance (Figure 3). Across different cars in our data, the price of driving one kilometer, i.e. the product of fuel price $p_{f}$ and fuel consumption $\phi$ (which is measured in liters per $100 \mathrm{~km}^{13}$ ), covers a wide range from $€ 2.60$ per $100 \mathrm{~km}$ up to $€ 30.9$ per $100 \mathrm{~km}$ depending on the car. However, the mean price of the $\mathrm{km}$ for new cars is more stable over our study period than the fuel prices (Figure 3). This may suggest a purchaser reaction counteracting price evolution: fuel price variations are not entirely reflected in the average price-per-km, as they may be partly absorbed by variations in fuel consumption of purchased cars.

However, diesel cars produce more $\mathrm{CO}_{2}$ than gasoline cars: one liter of gasoline is transformed to $2.33 \mathrm{~kg}$ of $\mathrm{CO}_{2}$ while one liter of diesel is transformed to $2.63 \mathrm{~kg}$ of $\mathrm{CO}_{2} .^{14}$ Diesel cars also produce a long list of other toxic gases beyond $\mathrm{CO}_{2}$, as well as particulate matter (see e.g. Cames \& Helmers, 2013). As a consequence, there are calls to adjust diesel taxation. Two policies are under discussion: either to raise the level of diesel taxation per liter to the level of gasoline taxes or to introduce a "carbon tax" that is indexed on the $\mathrm{CO}_{2}$ emissions of each fuel, i.e. increasing both fuels' taxes proportionally to the $\mathrm{CO}_{2}$

\footnotetext{
${ }^{12}$ Consumption tax on energy products, "Taxe intérieure de consommation sur les produits énergétiques" (TICPE).

${ }^{13}$ Throughout this paper we use fuel consumption $\phi$ measured in liters per $100 \mathrm{~km}$; this is the inverse of fuel efficiency measured in miles per gallon (MPG), which is often used in the US.

${ }^{14}$ The differences in $\mathrm{CO}_{2}$ emissions are due to the differences in density of the fuel-types, see for example Demirel (2012). The mass of $\mathrm{CO}_{2}$ per liter of fuel that weights less than a $\mathrm{kg}$ might seem surprising; it results of the association of carbon elements from the fuel and ambient oxygen.
} 
emissions per liter. In the following, we estimate the consequences of both of these policies.

Beyond fuel taxation, firms face an annual tax related both to the $\mathrm{CO}_{2}$ class and to the fuel-type. Prior to 2004, the amount of this tax depended on horsepower; since 2004, it depends on $\mathrm{CO}_{2}$ class, which is closely related to horse power but slightly less favorable to diesel cars. ${ }^{15}$ As it may impact the preferences of firms towards one or other class, we use dummies for $\mathrm{CO}_{2}$ classes in our estimations.

\subsection{Fuel prices and cost per kilometer}

We focus on the extent to which consumers take fuel prices into account when buying a new vehicle via the cost of driving. Our main variable of interest is thus the expected cost $E\left(p_{j f t}^{k m}\right)$ at time $t$ for the amount of fuel $f$ needed to drive one $\mathrm{km}$ with the car $j f$. By definition, it depends on the car's fuel consumption $\phi_{j f}$, its fuel-type $f$ (diesel or gasoline) and the fuel prices:

$$
E\left(p_{j f t}^{k m}\right)=100 \times \phi_{j f}\left[\mathbb{1}_{f=\text { diesel }} E_{t}\left(p_{D}\right)+\mathbb{1}_{f=\text { gas }} E_{t}\left(p_{G}\right)\right],
$$

where $\phi_{j f}$ denotes the characteristic fuel consumption (in L/100 km), $p_{D}$ and $p_{G}$ the fuel prices including tax for one liter of diesel and gasoline, respectively.

As a car is a durable good, the decision to buy a given product $j f$ at time $t$ should take into account the discounted utility of the future utilization of this car net of operating cost. In particular, the purchaser should consider not only the current fuel prices at the time of purchase, but its expected changes in the future. We thus need an assumption on how purchasers forecast future gasoline prices: according to Anderson et al. (2013), consumer beliefs regarding future fuel prices are indistinguishable from a no change forecast, consistent for example with fuel prices following a random walk. However, given that new cars are seldom sold "off the rack," it usually takes a few months between purchase and the actual delivery and registration, which is our point of data collection. Thus, in our estimates, we do not use the contemporaneous fuel price but rather a three months lag of fuel prices. A slightly more sophisticated approach would have been to use moving average, which may be consistent with a purchaser belief in mean-reversion of fuel prices. In a model similar to ours, Klier \& Linn (2013) use both current fuel prices and moving averages, and observe that both alternative hypothesis on consumer beliefs yield very similar estimates.

\subsection{Demographic groups}

In order to account for heterogeneous preferences, we split our sample into three firm sectors and three types of private consumers. We further differentiate types based on geography and (for households only) expected income, resulting in 30 distinct demographic

\footnotetext{
${ }^{15}$ The yearly amount of the tax ranges from 750 euros for the smaller cars to 4,500 euros for the biggest ones in 2014.
} 
groups of car purchasers.

Figure 4: Overview of spatial variation in fuel consumption and share of diesel cars

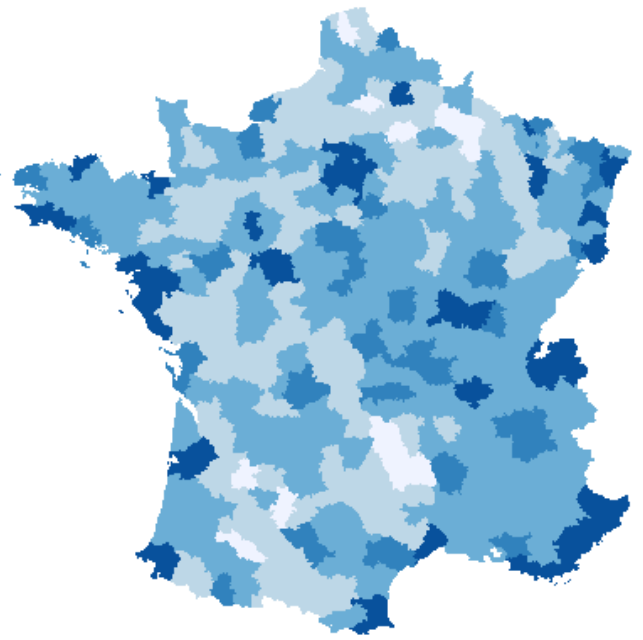

Share diesel sales

- $48-68 \%$

$65-70 \%$

ㄱ $70-75 \%$

$75-80 \%$

ㅁ over $80 \%$

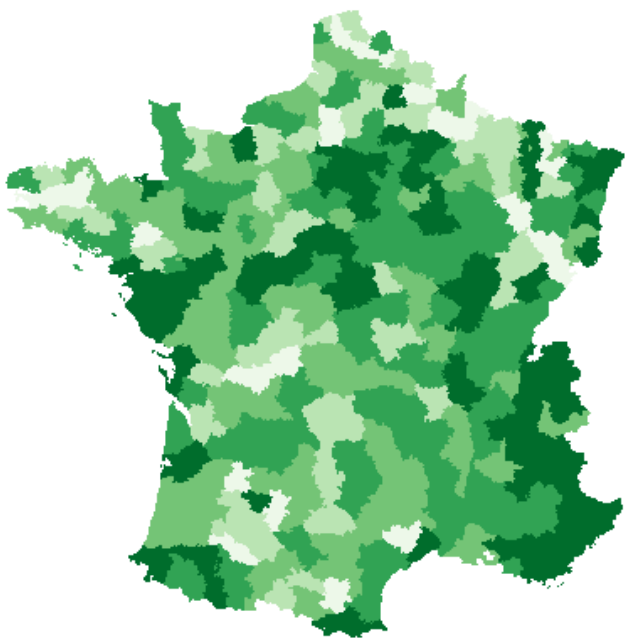

Mean fuel consumption ( $\mathrm{L} / \mathrm{km})$

$\square$ below $5.7 \mathrm{l} / \mathrm{km}$

5.7-5.8

․8-5.9

5.9-6

- over $6 \mathrm{l} / \mathrm{km}$

Source: CCFA, authors' calculations.

These categories aim at capturing factors essential to vehicle choice. Vehicle purchasers are likely to take into account factors such as the frequency and duration of use, the space needed, as well as the luxury-price trade-off. Moreover, one would like to consider the extent to which a buyer can substitute to other means of transports (bike, public transport, etc.).

For both private consumers and firms, we differentiate between types of residence areas. Residence area (rural or urban) accounts for differences in average travel distance and the availability of means of transport other than the car. In particular, the Paris region (Île-de-France) is considerably different from the rest of France, both in terms of economic development and its access to a dense public transportation network. Baccaini et al. (2007) show that the types of residence areas and in particular also Paris and its surroundings considerably differ regarding their average travel times and distances (see also Figure 5 in Appendix). Residence area is derived from the postal code: it allows us to sort areas of 
residence between urban Paris, the larger Paris metropolitan region. ${ }^{16}$ other urban areas and suburban/rural zones. Descriptive statistics confirm that purchasers from different area groups differ in terms of fuel efficiency and fuel-type of vehicles purchased, which pleads for controlling for geographical heterogeneity (cf. Tables 2 and 3 , or Fig. 4 ).

As shown in Clerc \& Marcus (2009), French private consumer elasticity to fuel prices largely depends on whether the consumer uses their car to go to work, as commuting represents the majority of kilometers driven in France. Activity status is thus an additional important factor for private owners. We consider the three groups: young employed (under the age of 30), employed (over 30-year-old) and not employed, with the latter including retirees, the unemployed and students.

We moreover split the private household groups according to income. We proxy the buyers' income by the median earnings by age at the precise municipality ("commune") of each purchaser of new cars and define two groups corresponding to the upper and lower half of this distribution. As group sizes are smaller in the Paris region, we do not distinguish along income dimensions for this region (see Table 10 in the Appendix for group sizes).

For firms, we differentiate with respect to the business sector: industry and agriculture, car trade and repairing, trade and services.

Descriptive statistics confirm that fuel efficiency of purchased cars is not homogeneous across purchaser types: private consumers living in a rural area, outside of the Paris region or who are young and employed tend to buy more fuel-efficient cars (Table 2). This is most likely linked to the fact that consumers expecting a high mileage pay more attention to fuel efficiency. Revenue also plays a role with more affluent consumers buying less efficient cars, which is more likely to be linked to preferences about comfort and quality than to mileage. There is variation across groups with a maximum difference between $€ 7.38$ (urban Paris and not employed) and $€ 6.16$ (rural, young employed and low income). Among firm purchases, we see that firms outside the Paris region tend to buy more fuel-efficient cars, and especially the ones working in trade and services.

\footnotetext{
${ }^{16}$ In the following, we use the term "Paris" or "urban Paris" for Paris and its close and densely populated suburbs (departments Paris (75), Hauts-de-Seine (92), Seine-Saint-Denis (93), Val-de-Marne (94) and some adjoining municipalities) while "Paris metropolitan region" describes the rest of the Île-de-France region.
} 
Table 2: Cost of driving $100 \mathrm{~km}$ with purchased car (in $€$ ) by group of buyers

\begin{tabular}{|c|c|c|c|c|c|c|}
\hline \multicolumn{7}{|c|}{$\underline{\text { Private consumers }}$} \\
\hline \multirow[b]{2}{*}{ Income } & \multicolumn{2}{|c|}{ Not employed } & \multicolumn{2}{|c|}{ Young employed $(<30)$} & \multicolumn{2}{|c|}{ Employed $(\geq 30)$} \\
\hline & Low & High & Low & High & Low & High \\
\hline Urban & 6.88 & 6.83 & 6.43 & 6.59 & 6.82 & 6.86 \\
\hline Suburb./rural & 6.58 & 6.63 & 6.16 & 6.31 & 6.50 & 6.56 \\
\hline Paris urban & \multicolumn{3}{|c|}{7.38} & 6.86 & \multicolumn{2}{|r|}{7.20} \\
\hline Paris metrop. & \multicolumn{2}{|r|}{6.89} & & 6.50 & \multicolumn{2}{|r|}{6.68} \\
\hline \multicolumn{7}{|c|}{ Firm purchases } \\
\hline Sector & \multicolumn{3}{|c|}{$\begin{array}{l}\text { Agriculture \& } \\
\text { industry }\end{array}$} & $\begin{array}{l}\text { Car trade \& } \\
\text { repairing }\end{array}$ & \multicolumn{2}{|c|}{$\begin{array}{l}\text { Trade \& } \\
\text { services }\end{array}$} \\
\hline Urban & \multicolumn{3}{|c|}{6.38} & 6.57 & \multicolumn{2}{|c|}{6.15} \\
\hline Suburban/rural & \multicolumn{3}{|c|}{6.40} & 6.13 & \multicolumn{2}{|l|}{6.22} \\
\hline Paris urban & \multicolumn{3}{|c|}{7.04} & 7.01 & \multicolumn{2}{|l|}{6.71} \\
\hline Paris metropolit & \multicolumn{3}{|c|}{6.60} & 6.50 & \multicolumn{2}{|l|}{6.32} \\
\hline
\end{tabular}

Source: CCFA, authors' calculations.

As diesel cars are more fuel-efficient (see Table 11 in the Appendix for an overview) and have lower fuel prices, they are especially popular among consumers who drive large distances. Private customers living in suburban/rural areas or young employed are two groups who generally drive longer distances and, indeed, are more likely to own diesel cars (Table 3). Similarly, firms based outside the Paris region tend to own more diesel cars, especially those working in trade and services. Generally, the share of diesel cars is much larger among firm-owned vehicles than among private purchases. 
Table 3: Share of diesel sales by group of buyers

\begin{tabular}{|c|c|c|c|c|c|c|c|}
\hline \multicolumn{8}{|c|}{$\underline{\text { Private consumers }}$} \\
\hline \multirow[b]{2}{*}{ Income } & \multicolumn{2}{|c|}{ Not employed } & \multicolumn{3}{|c|}{ Young employed $(<30)$} & \multicolumn{2}{|c|}{ Employed $(\geq 30)$} \\
\hline & Low & High & Low & High & & Low & High \\
\hline Urban & 0.54 & 0.58 & 0.67 & 0.68 & & 0.55 & 0.59 \\
\hline Suburb./rural & 0.66 & 0.65 & 0.80 & 0.77 & & 0.68 & 0.69 \\
\hline Paris urban & \multicolumn{2}{|c|}{0.44} & \multicolumn{3}{|c|}{0.58} & \multicolumn{2}{|c|}{0.49} \\
\hline Paris metrop. & \multicolumn{2}{|c|}{0.59} & \multicolumn{3}{|c|}{0.71} & \multicolumn{2}{|c|}{0.65} \\
\hline \multicolumn{8}{|c|}{ Firm purchases } \\
\hline \multicolumn{3}{|l|}{ Sector } & & $\begin{array}{l}\text { Industry \& } \\
\text { agriculture }\end{array}$ & \multicolumn{2}{|c|}{$\begin{array}{c}\text { Car trade \& } \\
\text { repairing }\end{array}$} & $\begin{array}{l}\text { Trade \& } \\
\text { services }\end{array}$ \\
\hline \multicolumn{3}{|l|}{ Urban } & & 0.84 & \multicolumn{2}{|c|}{0.75} & 0.88 \\
\hline \multicolumn{3}{|l|}{ Suburban/rural } & & 0.91 & \multicolumn{2}{|c|}{0.78} & 0.93 \\
\hline \multicolumn{3}{|c|}{ Paris urban } & & 0.73 & \multicolumn{2}{|c|}{0.68} & 0.82 \\
\hline \multicolumn{3}{|c|}{ Paris metropolitan } & & 0.84 & \multicolumn{2}{|c|}{0.76} & 0.88 \\
\hline
\end{tabular}

Source: CCFA, authors' calculations.

\section{Estimation}

\subsection{Nested logit equations and elasticities}

We take advantage of the fact that our data provides detailed information on purchasers to account for consumer heterogeneity: we assume that systematic differences in the valuation of different car characteristics are captured by the characteristics of purchasers that we observe in our data. We thus use the 30 types of purchasers as specified in Section 3.4 and estimate our model separately for each type. This is an alternative to random coefficient models à la BLP (Berry et al. 1995) which are commonly used. These models recover unobserved heterogeneity of preferences, which is particularly useful when only aggregate market-level data is available. However, this comes at the cost of high computational complexity. This complexity has been shown to lead to numerical instability in some cases: Knittel \& Metaxoglou (2014) show cases where results to largely depend on starting values and optimization algorithms. As relevant heterogeneity is assumed to be observed and captured by the demographic groups here, we can use the more constrained nested logit model with group-specific coefficients (see also Grigolon \& Verboven, 2014 for a discussion).

Under the nested logit assumption we can easily obtain the probability that a purchaser chooses one specific car. The aggregation of individual choices across purchasers of the same demographic group allows us to recover the market shares of each product $j f$ (model $j$ of fuel-type $f$ ), up to an identifying normalization. As usual in the literature, identification 
stems from the normalization of the outside good's value to zero. As an intermediary step, we thus obtain a linear specification for the market share $s_{d j f t}$ of the product $j f$ at time $t$ among purchaser type $d$ relatively to $s_{d 0 t}$ the market share of the outside good for that same demographic group:

$$
\ln \left(s_{d j f t}\right)-\ln \left(s_{d 0 t}\right)=\alpha_{d}+\beta_{d} p_{j f t}^{k m}+\gamma_{1 d} p_{j f t}+\gamma_{2 d} X_{j f t}+\sigma_{d 1} \ln \left(s_{d f / j}\right)+\sigma_{d 2} \ln \left(s_{d j / s}\right)+\xi_{d j f t}
$$

where $s_{d f / j}=\frac{s_{d j f t}}{s_{d j t}}$ is the relative share of purchases of fuel-type $f$ within purchases of model $j$ in each month $t$ and $s_{d j / s}=\frac{s_{d j t}}{s_{d s t}}$ is the relative share of model $j$ within the sales of segment $s$.

However, these shares are defined over the whole potential market size, which in our case - as in virtually all cases - is unknown. Indeed, this market size corresponds to how many people consider buying a car in a given period and decide not to. As detailed information on this market size is unknown, using some approximation is a standard procedure in this literature (e.g. the seminal papers by McFadden, 1978 and Goldberg, 1995), using for example most recent estimates of the population size or the number of people holding a driver's license. This number very likely overstates the actual market as with durable goods like cars, most consumers do not consider buying a car every month. Moreover, while a large portion of new car registrations are made by firms and not private owners, it is not clear whether these approximations are relevant. Besides, these estimates are typically not updated frequently. Huang \& Rojas (2013) show both theoretically and practically that coefficients estimated using such a wrong market size may be considerably biased.

To avoid this potential bias, we reformulate Equation (3): by using quantities rather than market shares, we can move all elements containing total market share to the right-hand side and estimate it as part of the year-specific constant. Panel dataset such ours are necessary to estimate our resulting main equation:

$$
\ln \left(q_{d j f t}\right)=\alpha_{d}+\beta_{d} p_{j f t}^{k m}+\gamma_{1 d} p_{j f t}+\gamma_{2 d} X_{j f t}+\sigma_{d 1} \ln \left(s_{d f / j}\right)+\sigma_{d 2} \ln \left(s_{d j / s}\right)+\ln \left(q_{d 0 t}\right)+\xi_{d j f t},
$$

where $q_{d j f t}$ stands for the number of sales of product $j f$. The quantity of the outside good $q_{d 0 t}$ is then estimated with a yearly time dummy variable. Moreover, we control for brand fixed effects and the month. We also control for official $\mathrm{CO}_{2}$ classes in order to account for potential ecological preferences linked to the $\mathrm{CO}_{2}$ thresholds communicated to the purchaser (cf D'Haultfoeuille et al., 2013), as well as for taxes on a firm vehicle tax indexed on $\mathrm{CO}_{2}$ classes since 2004 .

Our parameter of interest is the parameter $\beta_{d}$ measuring sensitivity to fuel prices. Beyond the estimation of parameters in Equation (4), our main focus lies upon the resulting fuel price elasticity, which takes into account both direct and indirect effects of an increase in fuel prices in the market share of one specific car. One may show that this elasticity may 
be approximated by (see details of computation in the Appendix on page 36):

$$
\begin{aligned}
\eta_{\mathbf{d s j f}} & =\frac{\partial s_{d s j f} / s_{d s j f}}{\partial p^{e} / p^{e}} \\
& \approx\left(1+t^{V A T}\right) p^{e}\left(\frac{\beta_{d}}{1-\sigma_{1 d}} \phi_{s j f d}+\left(\frac{\beta_{d}}{1-\sigma_{2 d}}-\frac{\beta_{d}}{1-\sigma_{1 d}}\right) \bar{\phi}_{s j d}+\frac{\beta \sigma_{2 d}}{1-\sigma_{2 d}} \bar{\phi}_{s d}\right) .
\end{aligned}
$$

In order to give some intuition on this elasticity, we will discuss not only $\beta$, but also the combinations $\frac{\beta_{d}}{1-\sigma_{1 d}}$ and $\frac{\beta_{d} \sigma_{2 d}}{1-\sigma_{2 d}}$ in the empirical section.

\subsection{Endogenous variables and instruments}

Gas prices can be considered as exogenous in the French case, as France represents about 2\% of world oil consumption and produces less than $0.1 \%$ of the world production. ${ }^{17}$ French gas prices are defined by the international energy market, on which France has only a limited weight (while it may be not the case for the US, see Davis \& Kilian (2011) for a discussion).

By contrast, the vehicle price $p_{j f t}$ is endogenous, as it is the result of demand and supply which by assumption vary with the unobserved attractiveness defining the error term $\xi_{d j f t}$.

Different sets of instruments can be found in the literature. We use a set of instruments based on the characteristics of potential substitutes aiming at capturing market density (and thus beyond production cost, the potential variation in mark-ups) ${ }_{18}^{18}$ More specifically, in a multi-product Bertrand competition framework, one can derive a set of instruments based on the sums of each characteristics of other models produced by the same firm in the same segment and those of competing firms. This measure is computed twice; once over all products within the same nest, and another time over all products in all other nests.

Armstrong (2012) argued that in markets with a large number of heterogeneous goods, BLP instruments are not sufficiently strong anymore. We thus add cost-shifters, such as the prices of raw materials, may provide exogenous variations in market prices as they are related to supply but not demand. Thus, we use the price indices of iron (current and lagged value) and indices of export prices of tires as instruments, weighted by the car's weight. These cost shifters appear strongly correlated to vehicle prices.

Within segment, the market shares $s_{d j / s}$ is endogenous by definition. As for the price, we use BLP-style instruments for this variable and further add the number $J_{s}$ of offered goods per segment $s$.

\footnotetext{
${ }^{17}$ In 2009, see http://www.eia.gov/countries/country-data.cfm?fips=FR.

${ }^{18}$ In their seminal paper, Berry et al. (1995) show the rationale of such a set of instruments in a multiproduct Bertrand competition framework.
} 
Finally, we instrument the within-model market share $s_{d f / j}$ by the difference in characteristics of gasoline and diesel versions (as well as the difference in costs shifters for these two versions), capturing the relative attractiveness of each version.

We use the generalized method of moments to estimate Equation (4) separately for each demographic group, assuming these groups homogeneous enough to include only buyers with the same demand parameters.

\section{$5 \quad$ Empirical results}

\subsection{Sensitivity of demand with respect to fuel prices}

The coefficients $\beta_{d}$ measure each demographic group's direct sensitivity to fuel prices. As expected, $\beta_{d}$ is statistically significant for most demographic groups and is always negative when significantly different from zero: as fuel prices increase, the demand for any given car decreases (Table 12 on page 41). 19 We find substantial heterogeneity in the relative magnitude of $\beta$ across purchaser types, especially with respect to employment and, to a smaller extent, to location, with non linear cross effects. This heterogeneity in preferences in this parameter may reflect heterogeneous use of the cars, but also heterogeneous elasticity in the average driving. Some purchasers may reduce their average mileage more or less easily in case of higher fuel prices, for example because of alternative transport possibilities.

However, because of the nested logit specification, the magnitude of the parameters is not directly informative on the actual fuel prices elasticities. One has to consider indirect effects due to the correlation (and thus higher potential substitution) between gasoline and diesel versions of the same model captured by $\sigma_{d 1}$, as well as substitution within segment measured by $\sigma_{d 2}$. The estimates for these parameters are as expected all between 0 and 1. $\sigma_{d 1}$ is on average 0.5 implying a relatively high correlation between the two fuel-type versions of the same model (Table 13 on page 42 in the Appendix), while $\sigma_{d 2}$ is relatively low, on average 0.2 , implying a relatively low correlation within segments (Table 14 on page 43 in the Appendix). If the purchaser has a preference for a particular model, he substitutes much more easily between gas and diesel versions when fuel prices change, rather than switching to a different model (even of the same segment). Intensity of substitution between the gasoline and diesel versions of the same model appears to be higher in urban areas (including Paris urban and metropolitan areas) than in rural areas. Indeed, while diesel cars yield savings in running costs for long journeys, this advantage is not clear cut for city driving. Urban drivers may be more indifferent between both versions of the cars

\footnotetext{
${ }^{19}$ Tables for estimated coefficients are in the Appendix as they are not directly interpretable. Only the relevant combination of parameters and the final elasticities are stated within the body of this study.
} 
and thus substitute more easily between them.

Ultimately, our aim is to use these parameters to determine the aggregate impact on market shares, diesel shares and fuel efficiency. As discussed in Section 4 , this requires evaluating the corresponding combination of parameters such as they enter Equation (5). The fuel consumption of a car $\phi_{s j f}$, the average fuel consumption over its model $\bar{\phi}_{j}$ or other products in the same segment $\bar{\phi}_{s}$ are all of the same order of magnitude. However, $\frac{\beta}{1-\sigma_{1}}$ (Table 4 dominates the two others $\left(\frac{\beta}{1-\sigma_{2}}-\frac{\beta}{1-\sigma_{1}}\right)$ and $\frac{\beta \sigma_{2}}{1-\sigma_{2}}$ (see Tables 15 and 16 in the Appendix).

Among private consumers, the effect of fuel price increases is stronger for employed consumers (Table 4). Working people have to drive the more and traveling distances cannot be easily reduced; they are thus expected to be the more responsive to fuel price changes. This may be somewhat reduced in the Paris region, where more public transport alternatives are available. Sensitivity to fuel prices is not significantly different between high and low income populations in urban areas. In rural areas, on average private consumers living in high income municipalities react more to a change in fuel prices.

Generally, private consumers react more strongly to fuel prices than firms. Within firms, we see considerable heterogeneity (Table 4). The most responsive firms are in urban areas except Paris, and firms operating in car trade and repairing sectors in rural areas. In the Paris metropolitan region, sensitivity is particularly low and almost never significant. One can argue that representative and status value is important to firms and rules out substitution to smaller, more efficient cars.

The signs of the other variables' coefficients (not reported here, except the price coefficient in Table 17 in the Appendix) are as expected: the vehicle price impacts utility negatively, while the 5-door-dummy and horsepower impact it positively. The coefficient for diesel engines is small for most demographic groups; it can be negative or positive depending on the groups, expressing preference differences between purchaser types.

\subsection{Aggregate demand elasticities}

The previously discussed estimates cannot be directly interpreted as price elasticities. However, we use them to compute the elasticity of specific cars with respect to fuel prices and taxes by adding up group-specific reactions (refer to the Appendix for details on the computation of these elasticities, page 36 ). We then further analyze the aggregate effect of two policies on the share of diesel cars purchased, fuel consumption and $\mathrm{CO}_{2}$ emissions. First, we provide an estimate of the impact of the "carbon tax" proportional to actual emissions that has been voted in 2013 and due to take effect in 2016, then we provide an estimate of the impact of aligning the (currently more advantageous) diesel taxes on gasoline tax level. 
Table 4: Estimates for coefficient $\frac{\beta_{d}}{1-\sigma_{d 1}}$ (main parameter of elasticities to fuel prices)

\begin{tabular}{|c|c|c|c|c|c|}
\hline \multicolumn{6}{|c|}{ Private consumers } \\
\hline \multirow[b]{2}{*}{ Income } & \multicolumn{2}{|c|}{ Not employed } & Young employed $(<30)$ & \multicolumn{2}{|c|}{ Employed $(\geq 30)$} \\
\hline & Low & High & Low High & Low & High \\
\hline Urban & $\begin{array}{l}-0.18^{* * *} \\
(0.05)\end{array}$ & $\begin{array}{l}-0.15^{* * *} \\
(0.05)\end{array}$ & $\begin{array}{cc}-0.31^{* * *} & -0.26^{* * *} \\
(0.04) & (0.04)\end{array}$ & $\begin{array}{l}-0.30^{* * *} \\
(0.03)\end{array}$ & $\begin{array}{l}-0.34^{* * *} \\
(0.03)\end{array}$ \\
\hline Suburb./rural & $\begin{array}{l}-0.15^{* * *} \\
(0.05)\end{array}$ & $\begin{array}{l}-0.19^{* * *} \\
(0.04)\end{array}$ & $\begin{array}{cc}-0.17^{* * *} & -0.27^{* * *} \\
(0.03) & (0.04)\end{array}$ & $\begin{array}{l}-0.23^{* * *} \\
(0.04)\end{array}$ & $\begin{array}{l}-0.31^{* * *} \\
(0.03)\end{array}$ \\
\hline Paris urban & \multicolumn{2}{|c|}{$\begin{array}{l}-0.14^{* * *} \\
(0.03)\end{array}$} & $\begin{array}{l}-0.23^{* * *} \\
(0.05)\end{array}$ & \multicolumn{2}{|c|}{$\begin{array}{l}-0.26^{* * *} \\
(0.02)\end{array}$} \\
\hline Paris metrop. & \multicolumn{2}{|c|}{$\begin{array}{c}-0.03 \\
(0.02)\end{array}$} & $\begin{array}{l}-0.12^{* * *} \\
(0.03)\end{array}$ & \multicolumn{2}{|c|}{$\begin{array}{l}-0.24^{* * *} \\
(0.03)\end{array}$} \\
\hline \multicolumn{6}{|c|}{ Firm purchases } \\
\hline Sector & \multicolumn{2}{|c|}{$\begin{array}{l}\text { Industry \& } \\
\text { agriculture }\end{array}$} & $\begin{array}{l}\text { Car trade \& } \\
\text { repairing }\end{array}$ & \multicolumn{2}{|l|}{$\begin{array}{l}\text { Trade \& } \\
\text { services }\end{array}$} \\
\hline Suburban/rural & \multicolumn{2}{|c|}{$\begin{array}{l}0.00 \\
(0.02)\end{array}$} & $\begin{array}{l}-0.19^{* * *} \\
(0.04)\end{array}$ & \multicolumn{2}{|l|}{$\begin{array}{c}-0.06^{*} \\
(0.03)\end{array}$} \\
\hline Urban & \multicolumn{2}{|c|}{$\begin{array}{l}-0.11^{* * *} \\
(0.03)\end{array}$} & $\begin{array}{l}-0.13^{* * *} \\
(0.03)\end{array}$ & \multicolumn{2}{|l|}{$\begin{array}{l}-0.11^{* * *} \\
(0.02)\end{array}$} \\
\hline Paris urban & \multicolumn{2}{|c|}{$\begin{array}{l}-0.05^{* * *} \\
(0.02)\end{array}$} & $\begin{array}{c}-0.04 \\
(0.03)\end{array}$ & \multicolumn{2}{|l|}{$\begin{array}{l}0.00 \\
(0.02)\end{array}$} \\
\hline Paris metropolitan & \multicolumn{2}{|c|}{$\begin{array}{l}0.01 \\
(0.07)\end{array}$} & $\begin{array}{c}-0.01 \\
(0.04) \\
\end{array}$ & \multicolumn{2}{|l|}{$\begin{array}{c}-0.06 \\
(0.07)\end{array}$} \\
\hline
\end{tabular}

Source: CCFA, authors' calculations. Equation 4 is estimated by GMM separately for each type of purchasers. Other controlling variables include horsepower, brand fixed effects, segment fixed effects, class of $\mathrm{CO}_{2}$, month-year effects, and price. Instrumental variables for prices correspond to the price indices of iron (current and lagged value) and indices of export prices of tires, interacted with the car's weight; instrumental variables for intra-segment and intra-model market shares further include BLP-style instruments and differences of characteristics between gasoline and diesel versions. 
Demand for selected products. For a given product, the elasticity of total demand to fuel prices (or fuel taxes) depends on both car's fuel efficiency relative to competing products and on which part of the population predominantly consumes the given car (Table 5). For the sake of illustration, we compute different elasticities $\eta_{\mathbf{s j f}}$ implied by the previously presented $\beta$ for some selected cars, as well as the shifts in demand $\Delta^{t_{c}} s_{j}$ and $\Delta^{t_{D}} s_{j}$ corresponding to the carbon tax $\left(t_{c}\right)$ and the equalization of diesel and gasoline taxes $\left(t_{D}\right)$, respectively.

As expected, an increase in fuel prices (both gasoline and diesel) reduces demand for different cars $\left(\eta_{\mathbf{s j}}<0\right)$, but the magnitude may vary significantly. The carbon tax (implemented as an increase of $3.4 \mathrm{c} / \mathrm{L}$ for gasoline and of $4 \mathrm{c} / \mathrm{L}$ for diesel over a two years horizon) is estimated to decrease demand for gasoline and diesel cars $\left(\Delta^{t_{c}} s_{j}<0\right)$. The policy equalizing diesel and gasoline tax strongly lowers the demand for diesel cars $\left(\Delta^{t_{D}} s_{j}<0\right)$; for example the sales of the Audi A6 with diesel engine would decrease by $12.7 \%$ (Table 5). The increase of diesel fuel tax on gasoline car demand is small but significantly positive, reflecting a substitution effect.

Table 5: Demand elasticity for selected models with respect to fuel prices

\begin{tabular}{|c|c|c|c|c|c|c|}
\hline model (segment) & fuel & $\begin{array}{l}\mathrm{CO}_{2} \\
(\mathrm{~g} / \mathrm{km})\end{array}$ & $\begin{array}{l}\text { fuel- } \\
\text { cons. } \\
(\mathrm{L} / \mathbf{1 0 0} \\
\mathrm{km})\end{array}$ & $\eta_{\mathrm{sjf}}$ & $\begin{array}{l}\Delta^{t_{c}} s_{j} \\
(\%)\end{array}$ & $\begin{array}{l}\Delta^{t_{D}} s_{j} \\
(\%)\end{array}$ \\
\hline Audi A6 (sedan) & gasoline & 239.7 & 10.3 & $\begin{array}{l}-0.39^{* * *} \\
(0.03)\end{array}$ & $\begin{array}{l}-3.04^{* * *} \\
(0.26)\end{array}$ & $\begin{array}{l}1.56^{* * * *} \\
(0.18)\end{array}$ \\
\hline Audi A6 (sedan) & diesel & 204.4 & 7.8 & $\begin{array}{c}-0.33^{* * *} \\
(0.03)\end{array}$ & $\begin{array}{l}-2.84^{* * *} \\
(0.24)\end{array}$ & $\begin{array}{c}-12.68^{* * *} \\
(1.06)\end{array}$ \\
\hline Citroen C3 (city-car) & gasoline & 147.8 & 6.4 & $\begin{array}{c}-0.33^{* * *} \\
(0.02)\end{array}$ & ${ }^{-2.72^{* * *}}$ & $\begin{array}{l}2.23^{* * *} \\
(0.20)\end{array}$ \\
\hline Citroen C3 (city-car) & diesel & 112.8 & 4.3 & $\begin{array}{l}-0.18^{* * * *} \\
(0.01)\end{array}$ & $\begin{array}{l}-1.85^{* * *} \\
(0.10)\end{array}$ & $\begin{array}{c}-10.28^{* * *} \\
(0.52)\end{array}$ \\
\hline Peugeot 307 (sport) & gasoline & 192.9 & 8.3 & $\begin{array}{l}-0.40^{* * * *} \\
(0.02)\end{array}$ & $\begin{array}{l}-1.08^{* * * *} \\
(0.06)\end{array}$ & $\begin{array}{l}1.42^{* * *} \\
(0.07)\end{array}$ \\
\hline Peugeot 307 (sport) & diesel & 159.0 & 6.0 & $\begin{array}{l}-0.30^{* * * *} \\
(0.02)\end{array}$ & $\begin{array}{l}-2.60^{* * *} \\
(0.14)\end{array}$ & $\begin{array}{c}-14.94^{* * *} \\
(0.80)\end{array}$ \\
\hline Renault Twingo (compact) & gasoline & 137.0 & 5.9 & $\begin{array}{l}-0.31^{* * *} \\
(0.02)\end{array}$ & $\begin{array}{l}-2.56^{* * *} \\
(0.12)\end{array}$ & $\begin{array}{l}0.88^{* * *} \\
(0.04)\end{array}$ \\
\hline Renault Twingo (compact) & diesel & 113.0 & 4.3 & $\begin{array}{l}-0.22^{* * *} \\
(0.01)\end{array}$ & $\begin{array}{l}-1.81^{* * *} \\
(0.11)\end{array}$ & $\begin{array}{l}-10.30^{* * *} \\
(0.61)\end{array}$ \\
\hline
\end{tabular}

Source: CCFA, authors' calculations. Equation 4 is estimated by GMM separately for each type of purchasers. Standard errors are estimated by bootstrap (50 replications).

Aggregate elasticities to fuel price variation. Beyond the reaction of demand for individual products, we are interested in the aggregate impact of a change in fuel prices. From a policy perspective, the most interesting aspects are the impact on the share of 
diesel cars, on the mean fuel consumption and on the mean emission levels.

We assume that a change in underlying petrol prices through an international oil price shock impacts both gasoline and diesel prices. As diesel engines tend to be more efficient with an average fuel consumption of $5.7 \mathrm{~L} / 100 \mathrm{~km}$ versus $6.9 \mathrm{~L} / 100 \mathrm{~km}$ for gasoline engines (see Table 11 in the Appendix), a general fuel price increase would raise the share of diesel cars among new purchases $\pi^{D}$ (see Table 6) $2^{20}$ Consequently, the average fuel consumption would decrease as well as $\mathrm{CO}_{2}$ emission. However, all these effects have a small magnitude.

These results may be compared to previous estimates obtained in the literature, although few similar measures are computed for European markets. Using aggregated data on several European car markets, Klier \& Linn (2013) estimate that a $1 \$$ increase in fuel prices (per gallon) would increase the average miles-per-gallon (MPG) efficiency in France by 0.21 , implying an average fuel consumption elasticity $\eta_{\phi}$ of -0.017 . This value is similar to our estimate and much lower than the value they find for the US: there, $1 \$$ decreases the average MPG by 1.03, implying an average fuel consumption elasticity of 0.042 . Our estimate is somewhat smaller than the estimates by Clerides \& Zachariadis (2008), who find a short term elasticity of fuel consumption to fuel prices equal to -0.08 for the EU, using aggregate data and a reduced-form model.

Carbon tax. Using our estimates, we predict the impact of the recently voted carbon tax, i.e. a tax increase that is proportional to the carbon emissions of each fuel-type. In practice the amounts are relatively small for both types of fuel: the progressive implementation will result in an increase of 3.4 cent/liter of gasoline and 4 cent/liter of diesel in 2016 compared to their levels in 201321 This corresponds to a price of $€ 15$ per ton of $\mathrm{CO}_{2}$ and represents around 3 or $4 \%$ of the average end-user price. With such small variations, it seems not problematic to compute the impact using our estimated marginal elasticities.

The impact of this carbon tax policy on the share of diesel engines sold $\Delta^{t_{c}} \pi_{D}$ is positive, even though diesel tax is increased by a greater amount than gasoline tax. This (very small, but surprising) effect stems mostly from a composition effect: as Table 7 reveals, both private consumers and firms buy relatively fewer diesel engines. However, private consumers react much more on the extensive margin (substituting to the outside good and not buying a new car) so that the overall diesel share moves towards the (much higher) firm diesel share.

As such a tax increases end-user prices of both fuel-types, it pushes purchasers towards more fuel-efficient cars, but reduces both average fuel consumption as well as average $\mathrm{CO}_{2}$

\footnotetext{
${ }^{20}$ Note that $\pi^{D}$ is the market share of diesel cars among purchased cars whereas the market shares $s_{j}$, $s_{s}$ etc. are defined on the whole market including the outside good

${ }^{21}$ See the site of the French ministry of environment: http://www.developpement-durable.gouv.fr/ La-fiscalite-des-produits, 11221.html
} 
Table 6: Elasticities with respect to fuel prices: diesel share, fuel consumption $(\mathrm{L} / 100 \mathrm{~km})$ and $\mathrm{CO}_{2}$ levels $(\mathrm{g} / \mathrm{km})$

\begin{tabular}{llll}
\hline \hline & Diesel share $\pi^{D}$ & Fuel-cons. & $\mathrm{CO}_{2}$ \\
& $\eta_{D}$ & $\eta_{\phi}$ & $\eta_{\mathrm{CO}_{2}}$ \\
\hline Households & $0.04^{* * *}$ & $-0.02^{* * *}$ & $-0.02^{* * *}$ \\
& $(0.00)$ & $(0.00)$ & $(0.00)$ \\
Firms & $0.01^{* * *}$ & $-0.01^{* * *}$ & $-0.01^{* * *}$ \\
& $(0.00)$ & $(0.00)$ & $(0.00)$ \\
Total & $0.04^{* * *}$ & $-0.01^{* * *}$ & $-0.02^{* * *}$ \\
& $(0.00)$ & $(0.00)$ & $(0.00)$ \\
\hline \hline
\end{tabular}

Source: CCFA, authors calculations. Estimates rely on the parameters of Equation 4 estimated by GMM separately for each type of purchasers. Standard errors are estimated by bootstrap (50 replications).

emission level by only $-0.09 \%$ (Table 7 ). At an average fuel consumption level of $6 \mathrm{~L} / 100 \mathrm{~km}$, this corresponds to a significant but small decrease of less than $0.01 \mathrm{~L} / 100 \mathrm{~km}$.

Table 7: Impact of carbon tax and tax alignment on diesel share, fuel consumption $(\mathrm{L} / 100 \mathrm{~km})$ and $\mathrm{CO}_{2}$ levels $(\mathrm{g} / \mathrm{km})$

\begin{tabular}{|c|c|c|c|c|c|c|}
\hline & \multicolumn{3}{|c|}{ Carbon tax } & \multicolumn{3}{|c|}{ Tax alignment } \\
\hline & $\begin{array}{c}\text { Diesel share } \\
\qquad \Delta^{t_{c}} \pi^{D}\end{array}$ & $\begin{array}{l}\text { Fuel-cons. } \\
\qquad \Delta^{t_{c}} \bar{\phi}\end{array}$ & $\begin{array}{c}\mathrm{CO}_{2} \\
\Delta^{t_{c}} \mathrm{CO}_{2}\end{array}$ & $\begin{array}{c}\text { Diesel share } \\
\Delta^{t_{D}} \pi^{D}\end{array}$ & $\begin{array}{l}\text { Fuel-cons. } \\
\qquad \Delta^{t_{D}} \bar{\phi}\end{array}$ & $\begin{array}{c}\mathrm{CO}_{2} \\
\Delta^{t_{D}} \mathrm{CO}_{2}\end{array}$ \\
\hline Households & $\begin{array}{c}-0.03 \\
(0.02)\end{array}$ & $\begin{array}{l}-0.12^{* * *} \\
(0.01)\end{array}$ & $\begin{array}{l}-0.13^{* * *} \\
(0.01)\end{array}$ & $\begin{array}{l}-7.55^{* * *} \\
(0.36)\end{array}$ & $\begin{array}{l}0.51^{* * *} \\
(0.03)\end{array}$ & $\begin{array}{l}-0.12^{* * *} \\
(0.01)\end{array}$ \\
\hline Firms & $\begin{array}{c}-0.03^{* *} \\
(0.01)\end{array}$ & $\begin{array}{l}-0.05^{* * *} \\
(0.01)\end{array}$ & $\begin{array}{l}-0.06^{* * *} \\
(0.01)\end{array}$ & $\begin{array}{l}-1.61^{* * *} \\
(0.23)\end{array}$ & $\begin{array}{l}0.02^{* *} \\
(0.01)\end{array}$ & $\begin{array}{l}-0.16^{* * *} \\
(0.03)\end{array}$ \\
\hline Total & $\begin{array}{l}0.07^{* * *} \\
(0.02)\end{array}$ & $\begin{array}{l}-0.09^{* * *} \\
(0.01)\end{array}$ & $\begin{array}{l}-0.09^{* * *} \\
(0.01)\end{array}$ & $\begin{array}{l}-4.94^{* * *} \\
(0.24)\end{array}$ & $\begin{array}{l}0.35^{* * *} \\
(0.02)\end{array}$ & $\begin{array}{l}-0.11^{* * *} \\
(0.02)\end{array}$ \\
\hline
\end{tabular}

Source: CCFA, authors calculations. Estimates rely on the parameters of Equation 4 estimated by GMM separately for each type of purchasers. Instrumental variables for prices correspond to the price indices of iron (current and lagged value) and indices of export prices of tires, interacted with the car's weight. Standard errors are estimated by bootstrap (50 replications).

Tax alignment. We also estimate the impact of a policy that would equalize diesel and gasoline taxes. This represents a much bigger tax change, leaving gasoline taxes unchanged but raising diesel taxes by about a third from 44 cent/liter to 61 cent/liter. The impact of this policy is more complex.

As expected, the induced variation in diesel share is negative and strong: since taxes only increase for diesel, they would push many purchasers to substitute for a gasoline-fueled car. 
We find that such a policy would reduce the aggregate share of diesel cars in overall sales by $4.9 \%$, that is from $69 \%$ to $66 \%$ (Table 7 ). This decrease in diesel sales comes mostly from households that substitute much more easily away from diesel engines than firms ( $7.6 \%$ and $1.6 \%$ reduction, respectively). This result can be compared to the one in Klier \& Linn (2013) who also evaluate a hypothetical policy of equalizing diesel and gasoline prices. At the European level, their estimates suggest that the impact of such a policy on the market share of diesel cars would be negligible (less than 1\%). Two elements explain this difference. First, our analysis is focused on France, where the gap between gasoline and diesel taxation is the highest of all countries they consider: the hypothetical policy change is strong (which is not the case for other countries), so it is not surprising to predict a stronger reaction. ${ }^{22}$ Second, as they emphasize, Klier \& Linn (2013) cannot distinguish in their data company cars from privately owned cars. According to our estimates, firms are much less sensitive to fuel prices (Table 6).

However, diesel cars are more fuel-efficient but produce more $\mathrm{CO}_{2}$ per liter of fuel. The second considered policy thus increases fuel consumption (Table 7) and reduces the average $\mathrm{CO}_{2}$ emission level of newly purchased cars. Nevertheless, both effects are rather small: the considerable jump in diesel tax we consider increases average fuel consumption by $0.35 \%$ and decreases average $\mathrm{CO}_{2}$ emissions by $0.11 \%$. Again, the overall magnitudes of these changes are significant but small: fuel consumption would increase on average by $0.01 \mathrm{~L} / 100 \mathrm{~km}$ and $\mathrm{CO}_{2}$ emissions would be reduced on average by $0.16 \mathrm{~g} / \mathrm{km}$ (at a mean of $152 \mathrm{~g} / \mathrm{km})$.

The impact of both policies on fuel efficiency and $\mathrm{CO}_{2}$ emissions is thus economically small. The second policy induces a noticeable shift away from diesel engines that are shown to produce many other greenhouse gases as well as harmful particulate matter.

\subsection{Robustness checks}

Taking into account the correlation between fuel and gasoline versions comes at a price, as we restrict the sample size to models sold in both versions at one date. In order to test the sensitivity of our results to this restriction we use a more commonly used model using only two levels: purchasers choose a segment and then a product within that segment. The two fuel-type versions of a model then count as independent products, which is the same as constraining all $\sigma_{d 1}$ coefficients to zero. Table 8 shows that the results are similar with only a small increase in magnitude. Using the estimates to compute the reaction to our two policies of interest, this difference increases and we see that especially the impact on the diesel share is overestimated but the intuition remains unchanged (Table 9). Although the changes are small, we still reject this more constrained model as in our

\footnotetext{
${ }^{22}$ Estimates detailed by countries are available on a previous working paper (Klier \& Linn, 2011). They obtain that the diesel market share in France would decrease by 1.4 percentage points. This reduction is higher than the effect in most other countries they examine.
} 
main estimation $\sigma_{d 1}$ was significantly different from zero for almost all demographic groups.

Although our partition in demographic groups is based on demographic characteristics essential to the choice of a new car, one could ask about the impact of abolishing such a partition and assuming preferences homogeneous across the population. It appears that this specification gives a similar order of magnitude for the fuel price sensitivity parameter $\beta$. Bento et al. (2012) suggested that unaccounted heterogeneity biases estimated elasticity downwards, which we do not find here (Table 8). However, the carbon tax appears to decrease the diesel share (Table 9), while our main specification suggests an increase: as private consumers and firms are mixed here, we do not observe the impact of their different substitution patterns.

Our main specification still seems most appropriate, but these alternative specifications do not dramatically change the implications of our paper.

\section{Limitations}

This study aims at estimations demand side effects of fuel taxes. Although we carefully consider many caveats arising from our static choice model, it still has some limitations that should be discussed.

Other than most literature on this question, we do not assess the rationality (or myopia) of consumer's reaction to fuel price changes. Indeed, we do not use any data on mileage nor assume anything on car lifetime and discounting, so that we remain agnostic on the actual potential profit a consumer realizes with fuel efficiency. We see it as an advantage not to rely on very specific assumptions about utilization reaction of consumers. Nevertheless, back-of-the-envelope calculations suggest that reactions are too small to account fully for the change in operating cost if utilization remains constant. In this light, it appears especially surprising that firm purchases are even less reactive to fuel price changes than households' purchases. We are the first paper documenting this difference. Further research is needed to clarify whether this is due to households incurring a incomparably bigger mileage or whether there are behavioral and organizational factors at play.

Ultimately, the aim of environmental policy is not to increase fuel-efficiency, but to decrease $\mathrm{CO}_{2}$ emissions which result from the interaction of fuel-efficiency and mileage. Additional research is needed to clarify the impact of cars' fuel-efficiency on car mileage. Previous research suggests that rebound effects might reduce any impact on fuel-efficiency (see for example Austin \& Dinan, 2005), so that our (already small) estimated effects become even less economically and environmentally significant. Nevertheless, the change in the composition of the vehicle fleet impacts fuel consumption in the long run as cars are kept on 
Table 8: Elasticities with respect to fuel prices: diesel share, fuel consumption $(\mathrm{L} / 100 \mathrm{~km})$ and $\mathrm{CO}_{2}$ levels $(\mathrm{g} / \mathrm{km})$

\begin{tabular}{|c|c|c|c|}
\hline & Diesel share & Fuel-cons. & $\mathrm{CO}_{2}$ \\
\hline & $\eta_{D}$ & $\eta_{\phi}$ & $\eta_{\mathrm{CO}_{2}}$ \\
\hline \multicolumn{4}{|c|}{ Main specification - Nests (segment $>$ model $>$ fuel-type) } \\
\hline Households & $\begin{array}{l}0.04^{* * *} \\
(0.00)\end{array}$ & $\frac{-0.02^{* * *}}{(0.00)}$ & $\begin{array}{l}-0.02^{* * *} \\
(0.00)\end{array}$ \\
\hline Firms & $\begin{array}{l}0.01^{* * *} \\
(0.00)\end{array}$ & $\begin{array}{l}-0.01^{* * *} \\
(0.00)\end{array}$ & $\begin{array}{l}-0.01^{* * *} \\
(0.00)\end{array}$ \\
\hline Total & $\begin{array}{l}0.04^{* * *} \\
(0.00)\end{array}$ & $\begin{array}{l}-0.01^{* * *} \\
(0.00)\end{array}$ & $\begin{array}{l}-0.02^{* * *} \\
(0.00)\end{array}$ \\
\hline \multicolumn{4}{|c|}{ Alternative specification - Nests (segment $>$ product) } \\
\hline Households & $\begin{array}{l}0.06^{* * *} \\
(0.00)\end{array}$ & $\begin{array}{l}-0.02^{* * *} \\
(0.00)\end{array}$ & $\begin{array}{l}-0.02^{* * *} \\
(0.00)\end{array}$ \\
\hline Firms & $\begin{array}{l}0.01^{* * *} \\
(0.00)\end{array}$ & $\begin{array}{l}-0.01^{* * *} \\
(0.00)\end{array}$ & $\begin{array}{l}-0.01^{* * *} \\
(0.00)\end{array}$ \\
\hline Total & $\begin{array}{l}0.05^{* * *} \\
(0.00)\end{array}$ & $\begin{array}{l}-0.02^{* * *} \\
(0.00)\end{array}$ & $\begin{array}{l}-0.02^{* * *} \\
(0.00)\end{array}$ \\
\hline \multicolumn{4}{|c|}{ Main specification - No purchaser heterogeneity } \\
\hline Total & $\begin{array}{l}0.04^{* * *} \\
(0.00)\end{array}$ & $\begin{array}{l}-0.03^{* * *} \\
(0.00)\end{array}$ & $\begin{array}{l}-0.03^{* * *} \\
(0.00)\end{array}$ \\
\hline
\end{tabular}

Source: CCFA, authors calculations. Estimates rely on the parameter of Equation 4 estimated by GMM separately for each type of purchasers. Standard errors are estimated by bootstrap (50 replications). 
Table 9: Impact of carbon tax and tax alignment on diesel share, fuel consumption $(\mathrm{L} / 100 \mathrm{~km})$ and $\mathrm{CO}_{2}$ levels $(\mathrm{g} / \mathrm{km})$

\begin{tabular}{|c|c|c|c|c|c|c|}
\hline & \multicolumn{3}{|c|}{ Carbon tax } & \multicolumn{3}{|c|}{ Tax alignment } \\
\hline & $\begin{array}{l}\text { Diesel share } \\
\qquad \Delta^{t_{c}} \pi^{D}\end{array}$ & $\begin{array}{l}\text { Fuel-cons. } \\
\qquad \Delta^{t_{c}} \bar{\phi}\end{array}$ & $\begin{array}{c}\mathrm{CO}_{2} \\
\Delta^{t_{c}} \mathrm{CO}_{2}\end{array}$ & $\begin{array}{c}\text { Diesel share } \\
\Delta^{t_{D}} \pi^{D}\end{array}$ & $\begin{array}{l}\text { Fuel-cons. } \\
\qquad \Delta^{t_{D} \bar{\phi}}\end{array}$ & $\begin{array}{c}\mathrm{CO}_{2} \\
\Delta^{t_{D}} \mathrm{CO}_{2}\end{array}$ \\
\hline \multicolumn{7}{|c|}{ Main specification - Nests (segment $>$ model $>$ fuel-type) } \\
\hline Households & $\begin{array}{c}-0.03 \\
(0.02)\end{array}$ & $\begin{array}{l}-0.12^{* * *} \\
(0.01)\end{array}$ & $\begin{array}{l}-0.13^{* * *} \\
(0.01)\end{array}$ & $\begin{array}{l}-7.55^{* * *} \\
(0.36)\end{array}$ & $\begin{array}{l}0.51^{* * *} \\
(0.03)\end{array}$ & $\begin{array}{l}-0.12^{* * *} \\
(0.01)\end{array}$ \\
\hline Firms & $\begin{array}{l}-0.03^{* *} \\
(0.01)\end{array}$ & $\begin{array}{l}-0.05^{* * *} \\
(0.01)\end{array}$ & $\begin{array}{l}-0.06^{* * *} \\
(0.01)\end{array}$ & $\begin{array}{l}-1.61^{* * *} \\
(0.23)\end{array}$ & $\begin{array}{l}0.02^{* *} \\
(0.01)\end{array}$ & $\begin{array}{l}-0.16^{* * *} \\
(0.03)\end{array}$ \\
\hline Total & $\begin{array}{l}0.07^{* * *} \\
(0.02)\end{array}$ & $\begin{array}{l}-0.09^{* * *} \\
(0.01)\end{array}$ & $\begin{array}{l}-0.09^{* * *} \\
(0.01)\end{array}$ & $\begin{array}{l}-4.94^{* * *} \\
(0.24)\end{array}$ & $\begin{array}{l}0.35^{* * *} \\
(0.02)\end{array}$ & $\begin{array}{l}-0.11^{* * *} \\
(0.02)\end{array}$ \\
\hline \multicolumn{7}{|c|}{ Alternative specification - Nests (segment $>$ product) } \\
\hline Households & $\begin{array}{l}0.05^{* * *} \\
(0.02)\end{array}$ & $\begin{array}{l}-0.13^{* * *} \\
(0.01)\end{array}$ & $\begin{array}{l}-0.13^{* * *} \\
(0.00)\end{array}$ & $\begin{array}{l}-9.26^{* * *} \\
(0.30)\end{array}$ & $\begin{array}{l}0.80^{* * *} \\
(0.03)\end{array}$ & $\begin{array}{l}0.02^{* *} \\
(0.01)\end{array}$ \\
\hline Firms & $\begin{array}{c}-0.01 \\
(0.01)\end{array}$ & $\begin{array}{l}-0.07^{* * *} \\
(0.01)\end{array}$ & $\begin{array}{l}-0.08^{* * *} \\
(0.01)\end{array}$ & $\begin{array}{l}-2.27^{* * *} \\
(0.20)\end{array}$ & $\begin{array}{c}-0.01 \\
(0.01)\end{array}$ & $\begin{array}{l}-0.26^{* * *} \\
(0.03)\end{array}$ \\
\hline Total & $\begin{array}{l}0.15^{* * *} \\
(0.02)\end{array}$ & $\begin{array}{l}-0.11^{* * *} \\
(0.00)\end{array}$ & $\begin{array}{l}-0.10^{* * *} \\
(0.01)\end{array}$ & $\begin{array}{l}-6.24^{* * *} \\
(0.19)\end{array}$ & $\begin{array}{l}0.52^{* * *} \\
(0.02)\end{array}$ & $\begin{array}{l}-0.05^{* * *} \\
(0.02)\end{array}$ \\
\hline \multicolumn{7}{|c|}{ Main specification - No purchaser heterogeneity } \\
\hline Total & $\begin{array}{l}-0.02^{* * *} \\
(0.00)\end{array}$ & $\begin{array}{l}-0.17^{* * *} \\
(0.02)\end{array}$ & $\begin{array}{l}-0.18^{* * * *} \\
(0.02)\end{array}$ & $\begin{array}{l}-7.35^{* * *} \\
(0.84)\end{array}$ & $\begin{array}{l}0.48^{* * *} \\
(0.09)\end{array}$ & $\begin{array}{l}-0.23^{* * *} \\
(0.03)\end{array}$ \\
\hline
\end{tabular}

Source: CCFA, authors calculations. Estimates rely on the parameter of Equation 4 estimated by GMM separately for each type of purchasers. Instrumental variables for prices correspond to the price indices of iron (current and lagged value) and indices of export prices of tires, interacted with the car's weight. Standard errors are estimated by bootstrap (50 replications).

average for 13 years in France (Bilot et al., 2013).

Moreover, our effects are identified on relatively small variations. While under strict rationality assumptions, purchaser reaction should be scalable from smaller to bigger variation, we ignore all behavioral effects. The carbon tax considered in this study has a magnitude similar to observed fuel price variations. Still, a policy might have a signal effect beyond the simple cost-increase and might induce a more sizable shift in preferences. This effect can be reinforced by supply side reaction. Moreover, the considered policy equalizing diesel and gasoline tax is somewhat bigger in magnitude than fuel price variations used in this study, so that we cannot guarantee for nonlinearities in consumer reaction to bigger price changes.

Finally, an important limitation of this paper is that our simple demand model does not take into account long-run shifts on the supply-side. While one can be confident that the monthly fuel price variation used for identification in this article does not impact supply instantaneously, it is likely that producers react to long-term shifts: if fuel efficiency becomes more valuable, they might in the medium-run adjust their prices and in the long-run adjust the products developed and offered. For Klier \& Linn $(2013)$ this means that these 
short-run results underestimate the true impact on fuel efficiency and emissions, which would be enhanced by the producers' reaction. However, as shown by Verboven $(2002)$, producers' price reaction should counteract purchaser reaction to changes in differential fuel taxation. Klier \& Linn (2013) suggest that this is already observable on the French market: Using data for several European countries from 1991 to 1994, he observes that producers use the favorable diesel policy to put higher mark-ups on diesel cars. Bilot et al. (2013) obtain similar results on more recent period comparing gasoline and diesel versions of the same car in France and UK. Both of these producer-side reactions are ignored in our model, as this paper measures mainly the short to medium-term purchaser reaction. Finally however, producers are unlikely to change their offer drastically if consumer reaction is as small as our estimates suggest.

\section{Conclusion}

This paper estimates the impact of fuel prices on new automobile purchases of both households and firms. These estimates allow us to compute elasticities which we aggregate to estimate ex ante the impact of two tax reforms: first a "carbon tax", i.e. a tax increase proportional to $\mathrm{CO}_{2}$ emissions of each fuel-type, and second a tax reform increasing the diesel tax to the same level as gasoline tax. Using a nested logit specification, we control for hedonic valuation of a large range of car characteristics. Our individual registration data provides a potentially important advantage, as we can account for a considerable share of purchaser heterogeneity and our estimates are thus less prone to omitted sorting bias. We indeed find that purchaser types react differently to fuel tax changes. Most of aggregate market reaction comes from a consumption shift from urban and non working consumers; private consumers react more strongly than firms. To our knowledge, this important distinction between household and firm purchases has not been taken into the account in any previous literature.

The examined carbon tax, recently voted to be implemented in 2016, is expected to slightly increase the share of (relatively fuel-efficient) diesel cars among new purchases. It is expected to decrease both fuel consumption and $\mathrm{CO}_{2}$ emission level significantly, but the overall amounts stay low.

We also examine a possible policy equalizing tax levels on gasoline and diesel. This policy would decrease the share of diesel cars in sales more substantially from $69 \%$ to $66 \%$. As purchasers would substitute to (less efficient) gasoline cars, the average fuel consumption would rise in response to this policy, while at the same time average $\mathrm{CO}_{2}$ emission would slightly decrease as gasoline cars emit less $\mathrm{CO}_{2}$ per liter of used fuel. This effect is heterogeneous between different types of purchasers, especially between private consumers and firms.

All in all, these estimated effects of these two tax policies can be considered as small. They 
are short-term effects. In the long run, these effects might be larger if households react more to persistent shifts in prices and producers adjust the offered choice set. On the contrary, these estimates do not take into account an induced effect on mileage so that it is not possible to predict the overall change in $\mathrm{CO}_{2}$ emissions. 


\section{References}

Allcott, H. \& Wozny, N. (2014), 'Gasoline prices, fuel economy, and the energy paradox', Review of Economics and Statistics (forthcoming).

Anderson, S. T., Kellogg, R. \& Sallee, J. M. (2013), 'What do consumers believe about future gasoline prices?', Journal of Environmental Economics and Management 66(3), 383403.

Armstrong, T. (2012), 'Large market asymptotics for differentiated product demand estimators with economic models of supply'.

Austin, D. \& Dinan, T. (2005), 'Clearing the air: The costs and consequences of higher cafe standards and increased gasoline taxes', Journal of Environmental Economics and Management 50(3), 562-582.

Baccaini, B., Sémécurbe, F. \& Thomas, G. (2007), 'Les déplacements domicile-travail amplifiés par la périurbanisation', INSEE Première 1129, 1-4.

Bento, A. M., Li, S. \& Roth, K. (2012), 'Is there an energy paradox in fuel economy? a note on the role of consumer heterogeneity and sorting bias', Economics Letters 115(1), 4448 .

Berry, S., Levinsohn, J. \& Pakes, A. (1995), 'Automobile prices in market equilibrium', Econometrica 63, 841-890.

Berry, S. T. (1994), 'Estimating discrete-choice models of product differentiation', The RAND Journal of Economics 25(2), 242-262.

Bilot, H., Breteau, V. \& Weber, S. (2013), 'Quels effets d'un changement de taxation des carburants sur la diesélisation du parc automobile et les émissions de polluants ?', La revue du CGDD.

Busse, M. R., Knittel, C. R. \& Zettelmeyer, F. (2013), 'Are consumers myopic? Evidence from new and used car purchases', American Economic Review 103(1), 220-56.

Calvet, L. \& Marical, F. (2011), 'Consommation de carburant : effets des prix à court et à long terme par type de population', Économie et Statistique 446, 25-44.

Cames, M. \& Helmers, E. (2013), 'Critical evaluation of the European diesel car boomglobal comparison, environmental effects and various national strategies', Environmental Sciences Europe 25(1), 1-22.

Cardell, N. S. (1997), 'Variance components structures for the extreme-value and logistic distributions with application to models of heterogeneity', Econometric Theory 13(2), 185-213. 
Clerc, M. \& Marcus, V. (2009), Élasticités-prix des consommations énergétiques des ménages, Working Papers of the DESE, INSEE.

Clerides, S. \& Zachariadis, T. (2008), 'The effect of standards and fuel prices on automobile fuel economy: An international analysis', Energy Economics 30(5), 2657-2672.

Davis, L. W. \& Kilian, L. (2011), 'Estimating the effect of a gasoline tax on carbon emissions', Journal of Applied Econometrics 26(7), 1187-1214.

Demirel, Y. (2012), Energy: Production, Conversion, Storage, Conservation, and Coupling, Springer.

D'Haultfoeuille, X., Durrmeyer, I. \& Février, P. (2013), The Effect of Public Policies on Consumers' Preferences: Lessons from the French Automobile Market, Discussion Paper Series of SFB/TR 15 Governance and the Efficiency of Economic Systems 422, Humboldt University of Berlin.

D'Haultfœuille, X., Givord, P. \& Boutin, X. (2014), 'The environmental effect of green taxation: The case of the french bonus/malus', The Economic Journal 124(578), F444F480.

Goldberg, P. K. (1995), 'Product Differentiation and Oligopoly in International Markets: The Case of the U.S. Automobile Industry', Econometrica 63(4), 891-951.

Grigolon, L. \& Verboven, F. (2014), 'Nested logit or random coefficients logit?: A comparison of alternative discrete choice models of product differentiation', The Review of Economics and Statistics (forthcoming).

Hivert, L. (2013), 'Short-term break in the French love for diesel?', Energy Policy 54, 1122.

Huang, D. \& Rojas, C. (2013), 'The outside good bias in logit models of demand with aggregate data', Economics Bulletin 33(1), 198-206.

Klier, T. \& Linn, J. (2010), 'The price of gasoline and new vehicle fuel economy: Evidence from monthly sales data', American Economic Journal: Economic Policy 2(3), 134-153.

Klier, T. \& Linn, J. (2011), Fuel Prices and New Vehicle Fuel Economy in Europe, Working Papers 1117, Massachusetts Institute of Technology, Center for Energy and Environmental Policy Research.

Klier, T. \& Linn, J. (2013), 'Fuel prices and new vehicle fuel economy - comparing the united states and western europe', Journal of Environmental Economics and Management 66(2), 280-300.

Knittel, C. R. \& Metaxoglou, K. (2014), 'Estimation of random-coefficient demand models: Two empiricists' perspective', Review of Economics and Statistics 96(1), 34-59. 
Massé, E. (2005), 'Analyse économique de la rentabilité des filtres à particules sur les véhicules diesels neufs', Économie et Prévision 167(1), 13-25.

McFadden, D. (1978), Modeling the choice of residential location, in F. S. A. Karlqvist, L. Lundqvist \& J. Weibull, eds, 'Spatial Interaction Theory and Planning Models', North Holland: Amsterdam, pp. 75-96.

Miravete, E. J., Moral, M. J. \& Thurk, J. (2014), 'Protecting the european automobile industry through environmental regulation'.

Verboven, F. (1996), 'International price discrimination in the european car market', The RAND Journal of Economics 27(2), 240-268.

Verboven, F. (2002), 'Quality-based price discrimination and tax incidence: Evidence from gasoline and diesel cars', The RAND Journal of Economics 33(2), 275-297. 


\section{A Appendix}

\section{Descriptive statistics}

Table 10: Distribution of demographic groups among buyers (\%)

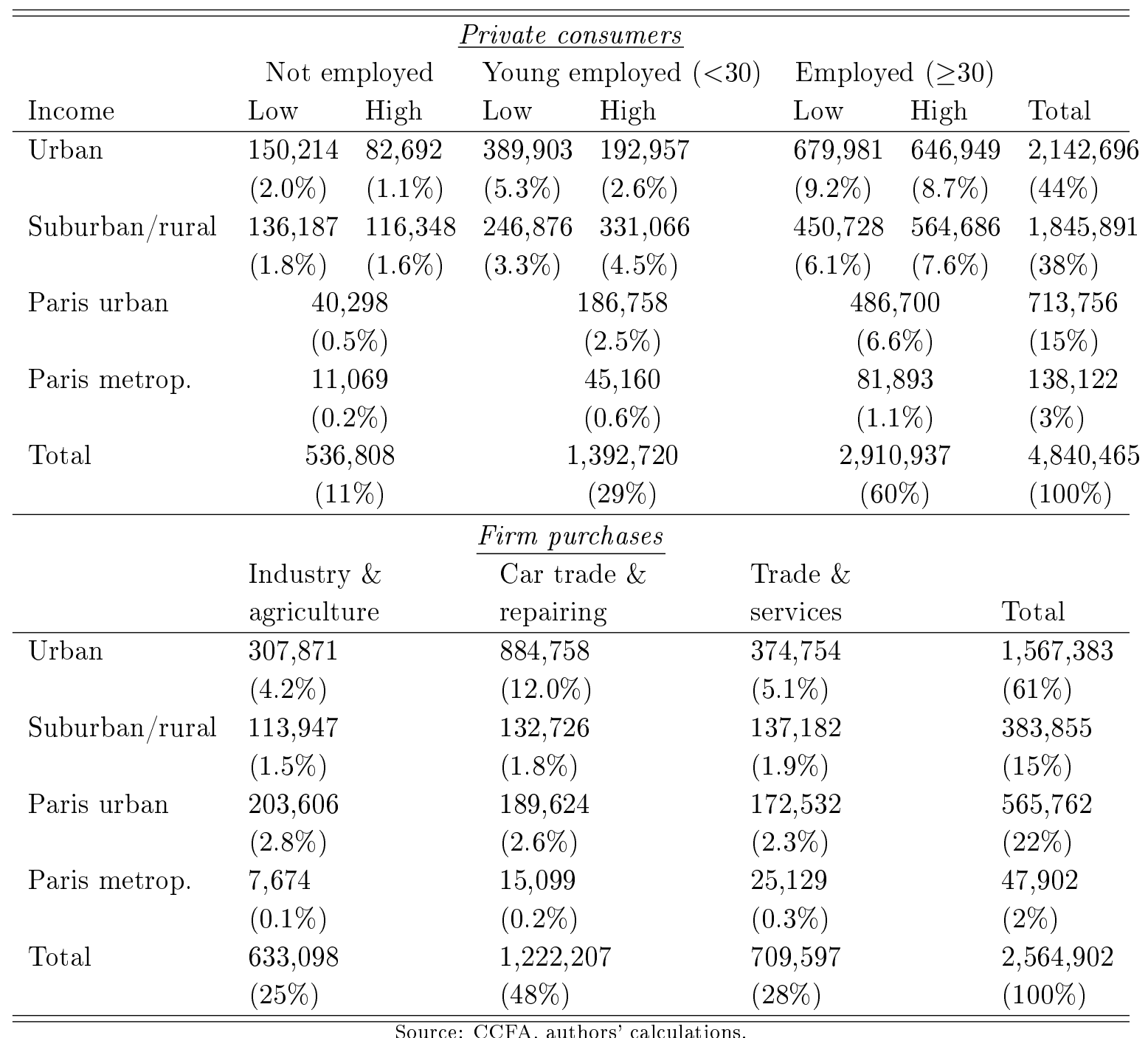


Table 11: Descriptive statics of key variables

\begin{tabular}{|c|c|c|c|c|c|}
\hline & \multirow[b]{2}{*}{ Mean } & \multirow[b]{2}{*}{$\begin{array}{c}\text { Coefficient } \\
\text { of variation }(\%)\end{array}$} & \multicolumn{3}{|c|}{ Percentiles } \\
\hline & & & $25 \%$ & median & $75 \%$ \\
\hline \multicolumn{6}{|l|}{ Gasoline $(\mathrm{N}=2,316,354)$} \\
\hline Car price $(€)$ & 16,890 & 68 & 11,783 & 14,133 & 19,000 \\
\hline Cost of driving $1 \mathrm{~km}(€)$ & 8.5 & 22.2 & 7.3 & 8.2 & 9.2 \\
\hline Horse power $(\mathrm{kW})$ & 71.7 & 48.3 & 54 & 64 & 81 \\
\hline Fuel consumption $(\mathrm{L} / 100 \mathrm{~km})$ & 6.9 & 21.4 & 6.0 & 6.6 & 7.4 \\
\hline $\mathrm{CO}_{2}$ emissions $(\mathrm{g} / \mathrm{km})$ & 160.4 & 21.4 & 139 & 153 & 173 \\
\hline \multicolumn{6}{|l|}{ Diesel $(\mathrm{N}=5,089,013)$} \\
\hline Car price $(€)$ & 23,271 & 40 & 16,850 & 22,040 & 26,533 \\
\hline Cost of driving $1 \mathrm{~km}(€)$ & 5.8 & 26.1 & 4.9 & 5.5 & 6.4 \\
\hline Horse power $(\mathrm{kW})$ & 79.6 & 33.0 & 63 & 79 & 92 \\
\hline Fuel consumption $(\mathrm{L} / 100 \mathrm{~km})$ & 5.7 & 23.7 & 4.7 & 5.4 & 6.0 \\
\hline $\mathrm{CO}_{2}$ emissions $(\mathrm{g} / \mathrm{km})$ & 148.8 & 23.7 & 124 & 143 & 159 \\
\hline
\end{tabular}

Note: The coefficient of variation, or unitized risk, is the ratio of the standard error to the mean.

Source: CCFA, authors' calculations. 


\section{Specificity of the Paris region}

Figure 5: Car utilization and demographic groups as used in estimations

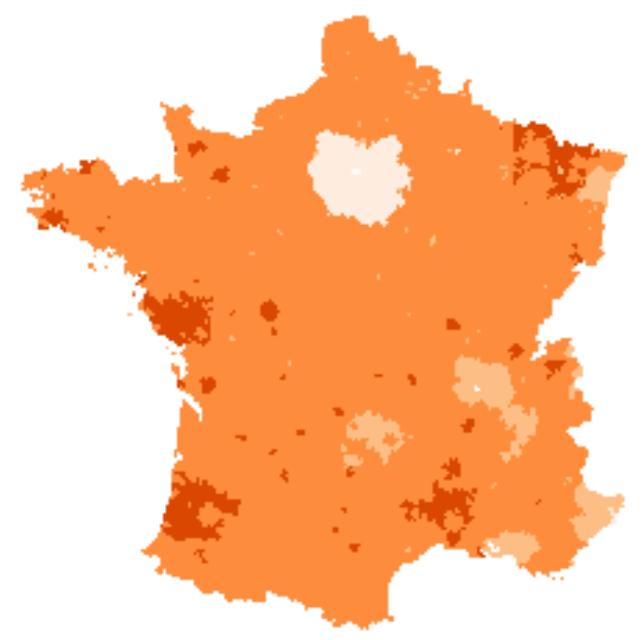

Share of population going to work by car

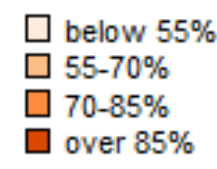

Source: 2007 population census by INSEE, authors' calculations. 


\section{Details on the computation of the elasticities}

The demand elasticity $\eta_{\mathbf{s j f}}$ for a given product with respect to oil price $p^{e}$ exclusive of tax at a given point in time can be computed using parameters corresponding to the demand model. Fuel prices affect all products proportionally to their fuel consumption: both the nominator and the denominator of the market shares are impacted. In order to find this elasticity, let us differentiate equation (3) for the model $j$ in segment $s$ and of fuel-type $f$, using the definition of the cost per kilometer ${ }^{23}$

$$
\frac{d s_{s j f}}{s_{s j f}}-\frac{d s_{0}}{s_{0}}=\beta d p^{e}\left(1+t^{V A T}\right) \phi_{s j f}+\sigma_{1}\left(\frac{d s_{s j f}}{s_{s j f}}-\frac{d s_{j}}{s_{j}}\right)+\sigma_{2}\left(\frac{d s_{j}}{s_{j}}-\frac{d s_{s}}{s_{s}}\right)
$$

or slightly rearranged:

$$
d s_{s j f}-\frac{d s_{0}}{s_{0}} s_{s j f}=\beta d p^{e}\left(1+t^{V A T}\right) \phi_{s j f} s_{s j f}+\sigma_{1}\left(d s_{s j f}-s_{s j f} \frac{d s_{j}}{s_{j}}\right)+\sigma_{2} s_{s j f}\left(\frac{d s_{j}}{s_{j}}-\frac{d s_{s}}{s_{s}}\right)
$$

We then aggregate this last equation over both fuel-type versions of the same model, in order to obtain the change in the market share of one model $j$ in one segment $s$ :

$$
\begin{aligned}
d s_{j}-\frac{d s_{0}}{s_{0}} s_{j}= & \sum_{f \in j}\left(d s_{s j f}-\frac{d s_{0}}{s_{0}} s_{s j f}\right) \\
= & \beta d p^{e}\left(1+t^{V A T}\right) \underbrace{\sum_{f \in j} \phi_{s j f} s_{s j f}}_{\bar{\phi}_{j} s_{j}} \\
& +\sigma_{1}(\underbrace{\sum_{f \in j} d s_{f j s}}_{d s_{j}}-\underbrace{\frac{d s_{j}}{s_{j}} \sum_{f \in j} s_{s j f}}_{d s_{j}}) \\
& +\sigma_{2}(\underbrace{d s_{j}}_{s_{j}}-\frac{d s_{s}}{s_{s}}) \underbrace{\sum_{f \in j} s_{s j f}}_{s_{j}}
\end{aligned}
$$

Thus we obtain that

$$
\left(1-\sigma_{2}\right) \frac{d s_{j}}{s_{j}}=\beta d p^{e}\left(1+t^{V A T}\right) \bar{\phi}_{j}-\sigma_{2} \frac{d s_{s}}{s_{s}}+\frac{d s_{0}}{s_{0}}
$$

Aggregating further, we can also recover the relative variation in the market share of segment $s\left(\frac{d s_{s}}{s_{s}}\right)$ or of the outside good $\left(\frac{d s_{0}}{s_{0}}\right)$ by summing on respectively all cars in the same segment, and all new cars. For segment $s$, we obtain that:

$$
\frac{d s_{s}}{s_{s}}=\beta d p^{e}\left(1+t^{V A T}\right) \bar{\phi}_{s}+\frac{d s_{0}}{s_{0}}
$$

\footnotetext{
${ }^{23}$ For the sake of readability, we omit the index for demographic groups and do not state the obvious aggregation over these groups for all equations in this section.
} 
while for the overall number of sold cars we get:

$$
\frac{d s_{0}}{s_{0}}=-\beta d p^{e}\left(1+t^{V A T}\right) \bar{\phi}\left(1-s_{0}\right)
$$

Combining these expressions in 6 we finally can compute the elasticity $\eta_{\mathbf{s j f}}$ as:

$$
\begin{aligned}
\eta_{\mathbf{s j f}} & =\frac{\partial s_{s j f} / s_{s j f}}{\partial p^{e} / p^{e}} \\
& =\beta\left(1+t^{V A T}\right) p^{e}\left(\rho_{1} \phi_{s j f}+\left(\rho_{2}-\rho_{1}\right) \bar{\phi}_{j}-\left(\rho_{2}-1\right) \bar{\phi}_{s}\right)-\beta\left(1+t^{V A T}\right) p^{e} \bar{\phi}\left(1-s_{0}\right), \\
& \approx \beta\left(1+t^{V A T}\right) p^{e}\left(\rho_{1}\left(\phi_{s j f}-\bar{\phi}_{j}\right)+\rho_{2}\left(\bar{\phi}_{j}-\bar{\phi}_{s}\right)+\bar{\phi}_{s}\right) .
\end{aligned}
$$

where $\rho_{i}=\frac{1}{1-\sigma_{i}} \in[1,+\infty]$. The demand elasticity depends on the parameter $\beta$ measuring sensitivity to fuel prices, the VAT rate $t^{V A T},{ }^{24}$ as well as on the current price of fuel and the car's fuel consumption $\phi_{s j f}$ relative to the average fuel economy of its substitutes (within the same model $\bar{\phi}_{j}$, within its segment $\bar{\phi}_{s}$ and among all sales $\bar{\phi}$ ). The share of the outside good $s_{0}$ is very close to 1 , as a monthly frequency is high compared to vehicle lifetime: most people do not buy a car in any given month and monthly sales are small compared to the market size. Thus, the second term involving $\bar{\phi}\left(1-s_{0}\right)$ is negligible.

The easier purchasers substitute between fuel-type versions of the same model (resp. between models within a segment), the higher is $\sigma_{1}$ (resp. $\sigma_{2}$ ) and thus the higher is $\rho_{1}$ (resp. $\rho_{2}$ ); intuitively speaking, a higher correlation of preference for similar products (same nests) leads to a relatively higher weight put onto the comparison with these similar products.

Obviously, diesel taxes affect cars differently depending on their fuel-type. Using our main model defined in Equation (4), the elasticity $\eta_{\mathbf{s j}}^{t_{D}}$ of demand for a given car $s j f$ with respect to an increase in diesel tax (holding gasoline tax constant) can be computed as:

$$
\begin{aligned}
\eta_{\text {sjf }}^{t_{D}}= & \frac{\partial s_{s j f} / s_{s j f}}{\partial t_{D} / t_{D}}, \\
= & \beta\left(1+t^{V A T}\right) t_{D}\left(\rho_{1}\left(\mathbb{1}_{f=\text { diesel }} \phi_{s j f}+\left(\rho_{2}-\rho_{1}\right) \pi_{j}^{D} \bar{\phi}_{j}-\left(\rho_{2}-1\right) \pi_{s}^{D} \bar{\phi}_{s}\right)\right. \\
& -\beta\left(1+t^{V A T}\right) t_{D} \bar{\phi}^{D} \pi^{D}\left(1-s_{0}\right), \\
\approx & \beta\left(1+t^{V A T}\right) t_{D}\left(\rho_{1}\left(\mathbb{1}_{f=\text { diesel }} \phi_{s j f}-\pi_{j}^{D} \bar{\phi}_{j}\right)+\rho_{2}\left(\pi_{j}^{D} \bar{\phi}_{j}-\pi_{s}^{D} \bar{\phi}_{s}\right)+\pi_{s}^{D} \bar{\phi}_{s}\right) .
\end{aligned}
$$

where the indicator $\mathbb{1}_{f=\text { diesel }}$ takes the value 1 if the vehicle $s j f$ is running on a diesel engine, $\pi_{s j}^{D}$ is the share of diesel in sales of model $j, \pi_{s}^{D}$ is the share of diesel in sales of segment $s$, and $\pi^{D}$ is the overall market share of new diesel cars (among purchases). $\bar{\phi}^{D}$ is the mean fuel consumption of new diesel cars (sales-weighted average). Again, $\left(1-s_{0}\right)$ is

\footnotetext{
${ }^{24}$ This is specific to the French form of petrol tax: as the fuel-type specific taxes are of a lump-sum form, they do not play a role here. The $t^{V A T}$ is the same for both fuel-types.
} 
close to zero and this elasticity can be closely approximated by the first part of the equation.

Intuitively, an increase in the diesel tax rate has a direct negative impact for all diesel cars. However, this effect may be reduced if its substitutes are also impacted by this increase. The effect for gasoline cars of a diesel tax is expected to be positive.

On a more aggregate level we examine the impact of an increase in fuel prices on the composition of the automobile fleet, with a particular focus on the amount of diesel cars purchased. More specifically, we evaluate the elasticity of the share of diesel cars among new purchases $\pi^{D}$. Assuming again that an international oil price shift equally affects both gasoline and diesel pre-tax prices, such a price shift would change the share of diesel cars by $\eta_{\mathbf{D}}$. In the simple logit demand, this can be computed as:

$$
\begin{aligned}
\eta_{\mathbf{D}} & =\frac{\partial \pi^{D} / \pi^{D}}{\partial p^{e} / p^{e}}, \\
& =\frac{\sum_{s, j, f} \mathbb{1}_{f=\text { diesel }} s_{s j f} \eta_{\mathbf{s j f}}}{\sum_{s, j, f} \mathbb{1}_{f=\text { diesel }} s_{s j f}}-\frac{\partial\left(1-s_{0}\right)}{\partial p^{e}} \frac{p^{e}}{1-s_{0}}, \\
& =\beta\left(1+t^{V A T}\right) p_{e}\left(\rho_{1}\left(\bar{\phi}^{D}-\widetilde{\bar{\phi}}_{j}\right)+\rho_{2}\left(\widetilde{\bar{\phi}}_{j}-\widetilde{\bar{\phi}}_{s}\right)+\widetilde{\bar{\phi}}_{s}-\bar{\phi}\right), \\
& =\frac{\beta\left(1+t^{V A T}\right) p_{e}}{\pi^{D}\left(1-s_{0}\right)} \sum_{s, j} s_{j}(\rho_{1} \underbrace{\pi_{j}^{D}\left(\phi_{j}^{D}-\bar{\phi}_{j}\right)}_{S_{1}}+\rho_{2} \underbrace{\left(\pi_{j}^{D}-\pi_{s}^{D}\right) \bar{\phi}_{j}}_{S_{2}}+\underbrace{\left(\pi_{s}^{D}-\pi^{D}\right) \bar{\phi}_{s}}_{S_{3}}),
\end{aligned}
$$

which involves weighted averages of fuel consumption, where the weights are given by the share of diesel sales. ${ }^{25} \widetilde{\bar{\phi}}_{j}=\sum_{s, j} \frac{\pi_{j}^{D} s_{j}}{\pi^{D}\left(1-s_{0}\right)} \bar{\phi}_{j}$ is the average fuel consumption weighted by the share of diesel per model, whereas $\widetilde{\bar{\phi}}_{s}=\sum_{s} \frac{\pi_{s}^{D} s_{s}}{\pi^{D}\left(1-s_{0}\right)} \bar{\phi}_{s}$ is the average weighted by the diesel share per segment. $\phi_{j}^{D}$ is the fuel consumption of the diesel version of model $j . \pi_{j}^{D}$, resp. $\pi_{s}^{D}$, is the share of diesel among purchases of model $j$, resp. of segment $s$.

The interpretation of this equation is not straightforward. In the simplest logit case $\left(\sigma_{1}=\sigma_{2}=0\right), \eta_{\mathbf{D}}=\beta\left(1+t^{V A T}\right) p_{e}\left(\bar{\phi}^{D}-\bar{\phi}\right)$. Quite naturally, $\eta_{\mathbf{D}}$ depends on the average fuel consumption of diesel cars relative to the overall average fuel consumption. $\bar{\phi}^{D}-\bar{\phi}$ is always negative because diesel cars are more fuel-efficient. $\beta$ is negative as well, so that $\eta_{\mathbf{D}}$ is positive: if fuel prices increase, purchasers substitute to more fuel-efficient diesel cars and their share among purchases increases.

In a nested setup the effect is less straightforward, but we still expect a positive sign. Indeed, the first term $S_{1}$ in Equation 10 involves the difference between diesel fuel con-

\footnotetext{
${ }^{25}$ With any variable $A$ we denote $\tilde{A}=\sum_{s, j, f} \frac{s_{s j f}}{\pi^{D}\left(1-s_{0}\right)} A_{s j f} \mathbb{1}_{f=\text { diesel }}$ this variable weighted by the share of the diesel version amongst all diesel cars (for example, $\widetilde{\phi}_{s j f}$ corresponds to the average fuel consumption of diesel cars $\bar{\phi}^{D}$ )
} 
sumption and average fuel consumption; again, this is expected to be negative as diesel engines tend to be more fuel-efficient. However, we do not have such an unambiguous relation for the two other terms $S_{2}$ and $S_{3} \cdot{ }^{26}$ Both $\rho_{1}$ and $\rho_{2}$ are positive and larger than one. In practice $\rho_{2}$ is smaller than $\rho_{1}$, so that $\eta_{\mathbf{D}}$ is most strongly impacted by the first element of the parenthesis, which is likely to be positive.

Similarly, the elasticity of the share of diesel cars $\pi^{D}$ to a change in fuel taxes (holding gasoline taxes constant) $\eta_{\mathbf{D}}^{t_{D}}$ may be written:

$$
\begin{aligned}
\eta_{\mathbf{D}}^{t_{D}} & =\frac{\partial \pi^{D} / \pi^{D}}{\partial t_{D} / t_{D}}, \\
& =\beta\left(1+t^{V A T}\right) p_{e}\left(\rho_{1}\left(\bar{\phi}^{D}-\widetilde{\pi_{j}^{D} \bar{\phi}_{j}}\right)+\rho_{2}\left(\widetilde{\pi_{j}^{D} \bar{\phi}_{j}}-\widetilde{\pi_{s}^{D} \bar{\phi}_{s}}\right)+\widetilde{\pi_{s}^{D \bar{\phi}}}-\bar{\phi}\right) .
\end{aligned}
$$

This elasticity $\eta_{\mathbf{D}}^{t_{D}}$ depends only on the fuel consumption of diesel cars and on their relative share among purchases: the lower their fuel consumption, the smaller the impact of a diesel tax increase.

Finally, we can also compute the elasticity $\eta_{\phi}$ (respectively $\eta_{\mathrm{CO}_{2}}$ ) of the average fuel consumption (respectively of average $\mathrm{CO}_{2}$ emission levels) of new cars with respect to fuel prices $p^{e}$ and to fuel taxes.

$$
\begin{aligned}
\eta_{\phi} & =\frac{\partial \bar{\phi} / \bar{\phi}}{\partial p^{e} / p^{e}}, \\
& =\beta\left(1+t^{V A T}\right) \frac{p_{e}}{\left(1-s_{0}\right) \bar{\phi}} \sum_{j, s, f}\left(\phi_{s j f} s_{s j f}\left(\rho_{1}\left(\phi_{s j f}-\bar{\phi}_{j}\right)+\rho_{2}\left(\bar{\phi}_{j}-\bar{\phi}_{s}\right)+\bar{\phi}_{s}-\bar{\phi}\right)\right)
\end{aligned}
$$

For example, in the simple logit demand model, $\eta_{\phi}$ simplifies to:

$$
\eta_{\phi}=\beta\left(1+t^{V A T}\right) p^{e}\left(\frac{\overline{\phi^{2}}-\bar{\phi}^{2}}{\bar{\phi}}\right),
$$

with $\overline{\phi^{2}}$ is the mean of squared fuel consumption of new vehicles. The impact of an oil price shock on average fuel consumption depends thus on the ratio of the variance and the mean of fuel consumption. Both the variance and the mean of $\phi$ are always positive, so that $\eta_{\phi}$ is always negative in the simple logit case: when fuel prices increase, we expect to find that average fuel consumption is reduced. In the more realistic nested logit demand model, the conclusion is less straightforward. Again, we have some intuition for the first

\footnotetext{
${ }^{26}$ The last term for example does not have a well defined sign. For example in the case of only two segments in proportion $s_{1}$ and $\left(1-s_{1}\right)$, this term is proportional to $s_{1}\left(1-s_{1}\right)\left(\pi_{s_{1}}^{D}-\pi_{s_{2}}^{D}\right)\left(\bar{\phi}_{s_{1}}-\bar{\phi}_{s_{2}}\right)$. One cannot exclude that this term is positive, for example if cars have a much higher fuel consumption in average in the segment with the higher share of diesel cars.
} 
term of Equation 13 which is of first order in the sum: it can be simplified rewritten as $\beta \rho_{1} \sum_{s, j} \pi_{j}^{D}\left(1-\pi_{j}^{D}\right) s_{j}\left(\phi_{j}^{D}-\phi_{j}^{G}\right)^{2}$ and is thus expected to be negative.

The elasticity of average fuel consumption $\eta_{\phi}^{t_{D}}$ (respectively $\eta_{\mathrm{CO}_{2}}^{t_{D}}$ ) to a change in diesel tax (holding gasoline tax constant) may be written in case of a simple logit demand model:

$$
\begin{aligned}
\eta_{\phi}^{t_{D}} & =\frac{\partial \bar{\phi} / \bar{\phi}}{\partial t_{D} / t_{D}}, \\
& =\beta t_{D}\left(1+t^{V A T}\right) \underbrace{\frac{\beta \pi^{D}}{\bar{\phi}}}_{<0}(\underbrace{\overline{\phi_{D}^{2}}-\bar{\phi}_{D}^{2}}_{>0}+\left(1-\pi^{D}\right) \bar{\phi}_{D} \underbrace{\left(\bar{\phi}_{D}-\bar{\phi}_{G}\right)}_{<0}) .
\end{aligned}
$$

This elasticity depends on the fuel consumption of diesel cars and on their relative share among purchases compared with the average fuel consumption. The sign is not clear-cut. An increase in the diesel tax may reduce the share of diesel cars, which are more fuelefficient. The higher the gap between the average fuel consumption of gasoline and diesel cars, the higher the increase in the average fuel emissions of new cars. This effect may be partially offset by the dispersion in fuel emissions of diesel cars, as we expect that an increase in diesel prices has more impact on the less fuel-efficient cars. All in all, we expect that a rise in diesel tax increases the average fuel emissions of new cars if diesel cars are much more fuel-efficient that gasoline cars and that the diesel share is not too high. 


\section{Complementary results}

\section{Estimates for remaining parameters in main specification}

Table 12: Estimates for coefficient $\beta_{d}$

\begin{tabular}{|c|c|c|c|c|c|c|c|}
\hline \multirow[b]{3}{*}{ Income } & \multicolumn{5}{|c|}{ Private consumers } & & \\
\hline & \multicolumn{3}{|c|}{ Not employed } & \multicolumn{2}{|c|}{ Young employed $(<30)$} & \multicolumn{2}{|c|}{ Employed $(\geq 30)$} \\
\hline & \multicolumn{2}{|c|}{ Low } & High & Low & High & Low & High \\
\hline Urban & \multicolumn{2}{|c|}{$\begin{array}{l}-0.10^{* * *} \\
(0.02)\end{array}$} & $\begin{array}{l}-0.08^{* * *} \\
(0.02)\end{array}$ & $\begin{array}{l}-0.16^{* * *} \\
(0.02)\end{array}$ & $\begin{array}{l}-0.13^{* * *} \\
(0.02)\end{array}$ & $\begin{array}{l}-0.14^{* * *} \\
(0.02)\end{array}$ & $\begin{array}{l}-0.14^{* * *} \\
(0.01)\end{array}$ \\
\hline Suburb./rural & \multicolumn{2}{|c|}{$\begin{array}{l}-0.08^{* * *} \\
(0.02)\end{array}$} & $\begin{array}{l}-0.11^{* * *} \\
(0.02)\end{array}$ & $\begin{array}{l}-0.11^{* * *} \\
(0.02)\end{array}$ & $\begin{array}{l}-0.16^{* * *} \\
(0.02)\end{array}$ & $\begin{array}{l}-0.11^{* * *} \\
(0.02)\end{array}$ & $\begin{array}{l}-0.15^{* * *} \\
(0.01)\end{array}$ \\
\hline Paris urban & \multicolumn{3}{|c|}{$\begin{array}{l}-0.10^{* * *} \\
(0.02)\end{array}$} & \multicolumn{2}{|c|}{$\begin{array}{l}-0.09^{* * *} \\
(0.02)\end{array}$} & \multicolumn{2}{|c|}{$\begin{array}{l}-0.10^{* * *} \\
(0.01)\end{array}$} \\
\hline Paris metrop. & \multicolumn{3}{|c|}{$\begin{array}{c}-0.03 \\
(0.02)\end{array}$} & \multicolumn{2}{|c|}{$\begin{array}{c}-0.08^{* * *} \\
(0.02)\end{array}$} & \multicolumn{2}{|c|}{$\begin{array}{c}-0.10^{* * *} \\
(0.01)\end{array}$} \\
\hline \multicolumn{8}{|c|}{ Firm purchases } \\
\hline Sector & \multicolumn{3}{|c|}{$\begin{array}{l}\text { Industry \& } \\
\text { agriculture }\end{array}$} & \multicolumn{2}{|c|}{$\begin{array}{l}\text { Car trade \& } \\
\text { repairing }\end{array}$} & \multicolumn{2}{|l|}{$\begin{array}{l}\text { Trade \& } \\
\text { services }\end{array}$} \\
\hline Suburban/rural & \multicolumn{3}{|c|}{$\begin{array}{l}0.00 \\
(0.01)\end{array}$} & \multicolumn{2}{|c|}{$\begin{array}{l}-0.11^{* * *} \\
(0.02)\end{array}$} & \multicolumn{2}{|l|}{$\begin{array}{l}-0.05^{* * *} \\
(0.02)\end{array}$} \\
\hline Urban & \multicolumn{3}{|c|}{$\begin{array}{l}-0.07^{* * *} \\
(0.02)\end{array}$} & \multicolumn{2}{|c|}{$\begin{array}{l}-0.06^{* * *} \\
(0.01)\end{array}$} & \multicolumn{2}{|l|}{$\begin{array}{l}-0.08^{* * *} \\
(0.01)\end{array}$} \\
\hline Paris urban & \multicolumn{3}{|c|}{$\begin{array}{l}-0.04^{* * *} \\
(0.02)\end{array}$} & \multicolumn{2}{|c|}{$\begin{array}{c}-0.02 \\
(0.01)\end{array}$} & \multicolumn{2}{|l|}{$\begin{array}{l}0.00 \\
(0.01)\end{array}$} \\
\hline \multicolumn{2}{|c|}{ Paris metropolitan } & \multicolumn{2}{|c|}{$\begin{array}{l}0.00 \\
(0.02)\end{array}$} & \multicolumn{2}{|c|}{$\begin{array}{c}-0.01 \\
(0.02)\end{array}$} & \multicolumn{2}{|l|}{$\begin{array}{c}-0.03 \\
(0.02)\end{array}$} \\
\hline
\end{tabular}

Source: CCFA, authors' calculations. Equation 4 is estimated by GMM separately for each type of purchasers. Other controlling variables include horsepower, brand fixed effects, segment fixed effects, class of $\mathrm{CO}_{2}$, month-year effects, and price. Instrumental variables for prices correspond to the price indices of iron (current and lagged value) and indices of export prices of tires, interacted with the car's weight; instrumental variables for intra-segment and intra-model market shares further include BLP-style instruments and differences of characteristics between gasoline and diesel versions. 
Table 13: Estimates for coefficient $\sigma_{1 d}$ (substitutability within model, between engine types)

\begin{tabular}{|c|c|c|c|c|c|c|c|}
\hline \multicolumn{8}{|c|}{ Private consumers } \\
\hline \multirow[b]{2}{*}{ Income } & \multicolumn{3}{|c|}{ Not employed } & \multicolumn{2}{|c|}{ Young employed $(<30)$} & \multicolumn{2}{|c|}{ Employed $(\geq 30)$} \\
\hline & \multicolumn{2}{|c|}{ Low } & High & Low & High & \multicolumn{2}{|c|}{ Low High } \\
\hline Urban & $\begin{array}{l}0.41^{*} \\
(0.04)\end{array}$ & $F^{* * *}$ & $\begin{array}{l}0.48^{* * *} \\
(0.04)\end{array}$ & $\begin{array}{l}0.50^{* * *} \\
(0.03)\end{array}$ & $\begin{array}{l}0.50^{* * *} \\
(0.03)\end{array}$ & $\begin{array}{l}0.55^{* * *} \\
(0.02)\end{array}$ & $\begin{array}{l}0.58^{* * *} \\
(0.02)\end{array}$ \\
\hline Suburb./rural & $\begin{array}{l}0.45^{*} \\
(0.04)\end{array}$ & $* * *$ & $\begin{array}{l}0.41^{* * *} \\
(0.03)\end{array}$ & $\begin{array}{l}0.38^{* * *} \\
(0.03)\end{array}$ & $\begin{array}{l}0.41^{* * *} \\
(0.03)\end{array}$ & $\begin{array}{l}0.54^{* * *} \\
(0.02)\end{array}$ & $\begin{array}{l}0.52^{* * *} \\
(0.02)\end{array}$ \\
\hline Paris urban & \multicolumn{3}{|c|}{$\begin{array}{l}0.30^{* * *} \\
(0.04)\end{array}$} & \multicolumn{2}{|c|}{$\begin{array}{l}0.62^{* * *} \\
(0.03)\end{array}$} & \multicolumn{2}{|c|}{$\begin{array}{l}0.61^{* * *} \\
(0.02)\end{array}$} \\
\hline Paris metrop. & \multicolumn{3}{|c|}{$\begin{array}{l}0.08 \\
(0.06)\end{array}$} & \multicolumn{2}{|r|}{$\begin{array}{l}0.34^{* * *} \\
(0.04)\end{array}$} & \multicolumn{2}{|c|}{$\begin{array}{l}0.57^{* * *} \\
(0.03)\end{array}$} \\
\hline \multicolumn{8}{|c|}{ Firm purchases } \\
\hline Sector & \multicolumn{3}{|c|}{$\begin{array}{l}\text { Industry \& } \\
\text { agriculture }\end{array}$} & \multicolumn{2}{|c|}{$\begin{array}{l}\text { Car trade \& } \\
\text { repairing }\end{array}$} & \multicolumn{2}{|l|}{$\begin{array}{l}\text { Trade \& } \\
\text { services }\end{array}$} \\
\hline \multicolumn{2}{|l|}{ Suburban/rural } & \multicolumn{2}{|c|}{$\begin{array}{l}0.28^{* * *} \\
(0.03)\end{array}$} & \multicolumn{2}{|c|}{$\begin{array}{l}0.45^{* * *} \\
(0.03)\end{array}$} & \multicolumn{2}{|l|}{$\begin{array}{l}0.27^{* * *} \\
(0.03)\end{array}$} \\
\hline Urban & \multicolumn{3}{|c|}{$\begin{array}{l}0.36^{* * *} \\
(0.03)\end{array}$} & \multicolumn{2}{|c|}{$\begin{array}{l}0.53^{* * *} \\
(0.02)\end{array}$} & \multicolumn{2}{|l|}{$\begin{array}{l}0.25^{* * *} \\
(0.03)\end{array}$} \\
\hline Paris urban & \multicolumn{3}{|c|}{$\begin{array}{l}0.22^{* * *} \\
(0.04)\end{array}$} & \multicolumn{2}{|c|}{$\begin{array}{l}0.49^{* * *} \\
(0.03)\end{array}$} & \multicolumn{2}{|l|}{$\begin{array}{l}0.19^{* * *} \\
(0.03)\end{array}$} \\
\hline \multicolumn{2}{|c|}{ Paris metropolitan } & \multicolumn{2}{|c|}{$\begin{array}{l}0.77^{* * *} \\
(0.05)\end{array}$} & \multicolumn{2}{|c|}{$\begin{array}{l}0.40^{* * *} \\
(0.05)\end{array}$} & \multicolumn{2}{|l|}{$\begin{array}{l}0.59^{* * *} \\
(0.05)\end{array}$} \\
\hline
\end{tabular}

Source: CCFA, authors' calculations. Equation 4 is estimated by GMM separately for each type of purchasers. Other controlling variables include horsepower, brand fixed effects, segment fixed effects, class of $\mathrm{CO}_{2}$, month-year effects, and price. Instrumental variables for prices correspond to the price indices of iron (current and lagged value) and indices of export prices of tires, interacted with the car's weight; instrumental variables for intra-segment and intra-model market shares further include BLP-style instruments and differences of characteristics between gasoline and diesel versions. 
Table 14: Estimates for coefficient $\sigma_{2 d}$ (substitutability within segment, between models)

\begin{tabular}{|c|c|c|c|c|c|c|c|}
\hline \multicolumn{8}{|c|}{ Private consumers } \\
\hline \multirow[b]{2}{*}{ Income } & \multicolumn{3}{|c|}{ Not employed } & \multicolumn{2}{|c|}{ Young employed $(<30)$} & \multicolumn{2}{|c|}{ Employed $(\geq 30)$} \\
\hline & Low & & High & Low & High & Low & High \\
\hline Urban & $\begin{array}{l}0.10^{*} \\
(0.02)\end{array}$ & & $\begin{array}{l}0.13^{* * *} \\
(0.02)\end{array}$ & $\begin{array}{l}0.22^{* * *} \\
(0.02)\end{array}$ & $\begin{array}{l}0.19^{* * *} \\
(0.02)\end{array}$ & $\begin{array}{l}0.32^{* * *} \\
(0.01)\end{array}$ & $\begin{array}{l}0.39^{* * *} \\
(0.01)\end{array}$ \\
\hline Suburb./rural & $\begin{array}{l}0.13^{*} \\
(0.02)\end{array}$ & & $\begin{array}{l}0.16^{* * *} \\
(0.02)\end{array}$ & $\begin{array}{l}0.22^{* * *} \\
(0.01)\end{array}$ & $\begin{array}{l}0.20^{* * *} \\
(0.01)\end{array}$ & $\begin{array}{l}0.28^{* * *} \\
(0.02)\end{array}$ & $\begin{array}{l}0.34^{* * *} \\
(0.01)\end{array}$ \\
\hline Paris urban & \multicolumn{3}{|c|}{$\begin{array}{l}0.17^{* * *} \\
(0.02)\end{array}$} & \multicolumn{2}{|c|}{$\begin{array}{l}0.25^{* * *} \\
(0.02)\end{array}$} & \multicolumn{2}{|c|}{$\begin{array}{l}0.37^{* * *} \\
(0.02)\end{array}$} \\
\hline Paris metrop. & \multicolumn{3}{|c|}{$\begin{array}{l}0.21^{* * *} \\
(0.02)\end{array}$} & \multicolumn{2}{|r|}{$\begin{array}{l}0.20^{* * *} \\
(0.02)\end{array}$} & \multicolumn{2}{|c|}{$\begin{array}{l}0.30^{* * *} \\
(0.02)\end{array}$} \\
\hline \multicolumn{8}{|c|}{ Firm purchases } \\
\hline Sector & \multicolumn{3}{|c|}{$\begin{array}{l}\text { Industry \& } \\
\text { agriculture }\end{array}$} & \multicolumn{2}{|c|}{$\begin{array}{l}\text { Car trade \& } \\
\text { repairing }\end{array}$} & \multicolumn{2}{|l|}{$\begin{array}{l}\text { Trade \& } \\
\text { services }\end{array}$} \\
\hline \multicolumn{2}{|l|}{ Suburban/rural } & \multicolumn{2}{|c|}{$\begin{array}{l}0.07^{* * *} \\
(0.02)\end{array}$} & \multicolumn{2}{|c|}{$\begin{array}{l}0.08^{* * *} \\
(0.02)\end{array}$} & \multicolumn{2}{|l|}{$\begin{array}{l}0.01 \\
(0.02)\end{array}$} \\
\hline Urban & \multicolumn{3}{|c|}{$\begin{array}{l}0.06^{* * *} \\
(0.02)\end{array}$} & \multicolumn{2}{|c|}{$\begin{array}{l}0.18^{* * *} \\
(0.02)\end{array}$} & \multicolumn{2}{|l|}{$\begin{array}{l}0.16^{* * *} \\
(0.02)\end{array}$} \\
\hline Paris urban & \multicolumn{3}{|c|}{$\begin{array}{l}0.12^{* * *} \\
(0.03)\end{array}$} & \multicolumn{2}{|c|}{$\begin{array}{l}0.25^{* * *} \\
(0.02)\end{array}$} & \multicolumn{2}{|l|}{$\begin{array}{l}0.23^{* * *} \\
(0.02)\end{array}$} \\
\hline \multicolumn{2}{|c|}{ Paris metropolitan } & \multicolumn{2}{|c|}{$\begin{array}{l}0.28^{* * *} \\
(0.03)\end{array}$} & \multicolumn{2}{|c|}{$\begin{array}{l}0.09^{* * *} \\
(0.02)\end{array}$} & \multicolumn{2}{|l|}{$\begin{array}{l}0.31^{* * *} \\
(0.03)\end{array}$} \\
\hline
\end{tabular}

Source: CCFA, authors' calculations. Equation 4 is estimated by GMM separately for each type of purchasers. Other controlling variables include horsepower, brand fixed effects, segment fixed effects, class of $\mathrm{CO}_{2}$, month-year effects, and price. Instrumental variables for prices correspond to the price indices of iron (current and lagged value) and indices of export prices of tires, interacted with the car's weight; instrumental variables for intra-segment and intra-model market shares further include BLP-style instruments and differences of characteristics between gasoline and diesel versions. 
Table 15: Estimates for coefficient $\beta_{d}\left(\frac{1}{1-\sigma_{d 2}}-\frac{1}{1-\sigma_{d 1}}\right)$

\begin{tabular}{|c|c|c|c|c|c|c|c|}
\hline \multicolumn{8}{|c|}{ Private consumers } \\
\hline \multirow[b]{2}{*}{ Income } & \multicolumn{3}{|c|}{ Not employed } & \multicolumn{2}{|c|}{ Young employed $(<30)$} & \multicolumn{2}{|c|}{ Employed $(\geq 30)$} \\
\hline & \multicolumn{2}{|c|}{ Low } & High & Low & High & Low & High \\
\hline Urban & \multicolumn{2}{|c|}{$\begin{array}{l}0.06^{* * *} \\
(0.02)\end{array}$} & $\begin{array}{l}0.06^{* * *} \\
(0.02)\end{array}$ & $\begin{array}{l}0.11^{* * *} \\
(0.02)\end{array}$ & $\begin{array}{l}0.10^{* * *} \\
(0.02)\end{array}$ & $\begin{array}{l}0.10^{* * *} \\
(0.02)\end{array}$ & $\begin{array}{l}0.11^{* * * *} \\
(0.02)\end{array}$ \\
\hline Suburb./rural & \multicolumn{2}{|c|}{$\begin{array}{l}0.05^{* *} \\
(0.02)\end{array}$} & $\begin{array}{l}0.06^{* * *} \\
(0.01)\end{array}$ & $\begin{array}{l}0.03^{* * *} \\
(0.01)\end{array}$ & $\begin{array}{l}0.07^{* * *} \\
(0.01)\end{array}$ & $\begin{array}{l}0.09^{* * *} \\
(0.02)\end{array}$ & $\begin{array}{l}0.08^{* * *} \\
(0.01)\end{array}$ \\
\hline Paris urban & \multicolumn{3}{|c|}{$\begin{array}{l}0.02 \\
(0.01)\end{array}$} & \multicolumn{2}{|c|}{$\begin{array}{l}0.11^{* * *} \\
(0.03)\end{array}$} & \multicolumn{2}{|c|}{$\begin{array}{l}0.10^{* * *} \\
(0.01)\end{array}$} \\
\hline Paris metrop. & \multicolumn{3}{|c|}{$\begin{array}{c}-0.01 \\
(0.01)\end{array}$} & \multicolumn{2}{|r|}{$\begin{array}{l}0.02 \\
(0.01) \\
\end{array}$} & \multicolumn{2}{|c|}{$\begin{array}{l}0.09^{* * *} \\
(0.02)\end{array}$} \\
\hline \multicolumn{8}{|c|}{ Firm purchases } \\
\hline Sector & \multicolumn{3}{|c|}{$\begin{array}{l}\text { Industry \& } \\
\text { agriculture }\end{array}$} & \multicolumn{2}{|c|}{$\begin{array}{l}\text { Car trade \& } \\
\text { repairing }\end{array}$} & \multicolumn{2}{|c|}{$\begin{array}{l}\text { Trade \& } \\
\text { services }\end{array}$} \\
\hline \multicolumn{2}{|l|}{ Suburban/rural } & \multicolumn{2}{|c|}{$\begin{array}{l}0.00 \\
(0.01)\end{array}$} & \multicolumn{2}{|c|}{$\begin{array}{l}0.08^{* * *} \\
(0.01)\end{array}$} & \multicolumn{2}{|l|}{$\begin{array}{l}0.02^{*} \\
(0.01)\end{array}$} \\
\hline Urban & \multicolumn{3}{|c|}{$\begin{array}{l}0.03^{* * *} \\
(0.01)\end{array}$} & \multicolumn{2}{|c|}{$\begin{array}{l}0.05^{* * *} \\
(0.01)\end{array}$} & \multicolumn{2}{|l|}{$\begin{array}{l}0.01 \\
(0.01)\end{array}$} \\
\hline Paris urban & \multicolumn{3}{|c|}{$\begin{array}{l}0.01 \\
(0.00)\end{array}$} & \multicolumn{2}{|c|}{$\begin{array}{l}0.01 \\
(0.01)\end{array}$} & \multicolumn{2}{|l|}{$\begin{array}{l}0.00 \\
(0.00)\end{array}$} \\
\hline \multicolumn{2}{|c|}{ Paris metropolitan } & \multicolumn{2}{|c|}{$\begin{array}{c}-0.01 \\
(0.04)\end{array}$} & \multicolumn{2}{|c|}{$\begin{array}{l}0.00 \\
(0.01)\end{array}$} & \multicolumn{2}{|l|}{$\begin{array}{l}0.03 \\
(0.03)\end{array}$} \\
\hline
\end{tabular}

Source: CCFA, authors' calculations. Equation 4 is estimated by GMM separately for each type of purchasers. Other controlling variables include horsepower, brand fixed effects, segment fixed effects, class of $\mathrm{CO}_{2}$, month-year effects, and price (/10,000 euros). Instrumental variables for prices correspond to the price indices of iron (current and lagged value) and indices of export prices of tires, interacted with the car's weight; instrumental variables for intra-segment and intra-model market shares further include BLP-style instruments and differences of characteristics between gasoline and diesel versions. 
Table 16: Estimates for coefficient $\frac{\beta_{d} \sigma_{d 2}}{1-\sigma_{d 2}}$

\begin{tabular}{|c|c|c|c|c|c|c|c|}
\hline \multicolumn{8}{|c|}{ Private consumers } \\
\hline \multirow[b]{2}{*}{ Income } & \multicolumn{3}{|c|}{ Not employed } & \multicolumn{2}{|c|}{ Young employed $(<30)$} & \multicolumn{2}{|c|}{ Employed $(\geq 30)$} \\
\hline & Low & & High & Low & High & Low & High \\
\hline Urban & $\begin{array}{r}-0.0 \\
(0.01)\end{array}$ & & $\begin{array}{l}-0.01^{*} \\
(0.01)\end{array}$ & $\begin{array}{l}-0.04^{* * *} \\
(0.01)\end{array}$ & $\begin{array}{l}-0.03^{* * *} \\
(0.01)\end{array}$ & $\begin{array}{l}-0.06^{* * *} \\
(0.01)\end{array}$ & $\begin{array}{l}-0.09^{* * *} \\
(0.01)\end{array}$ \\
\hline Suburb./rural & $\begin{array}{r}-0.0 \\
(0.01)\end{array}$ & & $\begin{array}{l}-0.02^{* * *} \\
(0.01)\end{array}$ & $\begin{array}{l}-0.03^{* * *} \\
(0.01)\end{array}$ & $\begin{array}{l}-0.04^{* * *} \\
(0.01)\end{array}$ & $\begin{array}{l}-0.04^{* * *} \\
(0.01)\end{array}$ & $\begin{array}{l}-0.08^{* * *} \\
(0.01)\end{array}$ \\
\hline Paris urban & \multicolumn{3}{|c|}{$\begin{array}{l}-0.02^{* * *} \\
(0.01)\end{array}$} & \multicolumn{2}{|c|}{$\begin{array}{c}-0.03^{* * *} \\
(0.01)\end{array}$} & \multicolumn{2}{|c|}{$\begin{array}{l}-0.06^{* * *} \\
(0.01)\end{array}$} \\
\hline Paris metrop. & \multicolumn{3}{|c|}{$\begin{array}{c}-0.01 \\
(0.01)\end{array}$} & \multicolumn{2}{|c|}{$\begin{array}{l}-0.02^{* * *} \\
(0.01)\end{array}$} & \multicolumn{2}{|c|}{$\begin{array}{l}-0.04^{* * *} \\
(0.01)\end{array}$} \\
\hline \multicolumn{8}{|c|}{ Firm purchases } \\
\hline Sector & \multicolumn{3}{|c|}{$\begin{array}{l}\text { Industry \& } \\
\text { agriculture }\end{array}$} & \multicolumn{2}{|c|}{$\begin{array}{l}\text { Car trade \& } \\
\text { repairing }\end{array}$} & \multicolumn{2}{|l|}{$\begin{array}{l}\text { Trade \& } \\
\text { services }\end{array}$} \\
\hline Suburban/rural & \multicolumn{3}{|c|}{$\begin{array}{l}0.00 \\
(0.00)\end{array}$} & \multicolumn{2}{|c|}{$\begin{array}{l}-0.01^{*} \\
(0.00)\end{array}$} & \multicolumn{2}{|l|}{$\begin{array}{l}0.00 \\
(0.00)\end{array}$} \\
\hline Urban & \multicolumn{3}{|c|}{$\begin{array}{l}0.00 \\
(0.00)\end{array}$} & \multicolumn{2}{|c|}{$\begin{array}{l}-0.01^{* * *} \\
(0.00)\end{array}$} & \multicolumn{2}{|l|}{$\begin{array}{l}-0.02^{* * *} \\
(0.01)\end{array}$} \\
\hline Paris urban & \multicolumn{3}{|c|}{$\frac{-0.01}{(0.00)}$} & \multicolumn{2}{|c|}{$\begin{array}{c}-0.01 \\
(0.01)\end{array}$} & \multicolumn{2}{|l|}{$\begin{array}{l}0.00 \\
(0.00)\end{array}$} \\
\hline \multicolumn{2}{|c|}{ Paris metropolitan } & \multicolumn{2}{|c|}{$\begin{array}{l}0.00 \\
(0.01)\end{array}$} & \multicolumn{2}{|c|}{$\begin{array}{l}0.00 \\
(0.00)\end{array}$} & \multicolumn{2}{|l|}{$\begin{array}{c}-0.01 \\
(0.01)\end{array}$} \\
\hline
\end{tabular}

Source: CCFA, authors' calculations. Equation 4 is estimated by GMM separately for each type of purchasers. Other controlling variables include horsepower, brand fixed effects, segment fixed effects, class of $\mathrm{CO}_{2}$, month-year effects, and price (/10,000 euros). Instrumental variables for prices correspond to the price indices of iron (current and lagged value) and indices of export prices of tires, interacted with the car's weight; instrumental variables for intra-segment and intra-model market shares further include BLP-style instruments and differences of characteristics between gasoline and diesel versions. 
Table 17: Estimates for the parameter corresponding to vehicle price (coefficient $\gamma_{d}$ in Equation 4), by type of purchasers

\begin{tabular}{|c|c|c|c|c|c|c|}
\hline \multicolumn{7}{|c|}{ Private consumers } \\
\hline \multirow[b]{2}{*}{ Income } & \multicolumn{2}{|c|}{ Not employed } & \multicolumn{2}{|c|}{ Young employed $(<30)$} & \multicolumn{2}{|c|}{ Employed $(\geq 30)$} \\
\hline & Low & High & Low & High & Low & High \\
\hline Urban & $\begin{array}{l}-0.64^{* * *} \\
(0.05)\end{array}$ & $\begin{array}{l}-0.57^{* * *} \\
(0.05)\end{array}$ & $\begin{array}{l}-0.30^{* * *} \\
(0.04)\end{array}$ & ${ }^{*}-0.31^{* * *}$ & $\begin{array}{l}-0.21^{* * *} \\
(0.03)\end{array}$ & $\begin{array}{l}-0.12^{* * *} \\
(0.03)\end{array}$ \\
\hline Suburb./rural & $\begin{array}{l}-0.66^{* * *} \\
(0.05)\end{array}$ & $\begin{array}{l}-0.66^{* * *} \\
(0.05)\end{array}$ & $\begin{array}{l}-0.43^{* * *} \\
(0.04)\end{array}$ & * ${ }^{-0.30^{* * *}}$ & $\begin{array}{l}-0.37^{* * *} \\
(0.03)\end{array}$ & $\begin{array}{l}-0.16^{\text {*** }} \\
(0.03)\end{array}$ \\
\hline Paris urban & \multicolumn{2}{|c|}{$\begin{array}{l}-0.35^{* * *} \\
(0.05)\end{array}$} & \multicolumn{2}{|c|}{$\begin{array}{c}-0.33^{* * *} \\
(0.04)\end{array}$} & \multicolumn{2}{|c|}{$\begin{array}{l}-0.21^{* * *} \\
(0.03)\end{array}$} \\
\hline Paris metrop. & \multicolumn{2}{|c|}{$\begin{array}{l}-0.19^{* * *} \\
(0.05)\end{array}$} & \multicolumn{2}{|c|}{$\begin{array}{l}-0.25^{* * *} \\
(0.04)\end{array}$} & \multicolumn{2}{|c|}{$\begin{array}{l}-0.13^{* * *} \\
(0.03)\end{array}$} \\
\hline \multicolumn{7}{|c|}{ Firm purchases } \\
\hline \multicolumn{2}{|l|}{ Sector } & \multicolumn{2}{|c|}{$\begin{array}{l}\text { Industry \& } \\
\text { agriculture }\end{array}$} & $\begin{array}{l}\text { Car trade \& } \\
\text { epairing }\end{array}$ & \multicolumn{2}{|l|}{$\begin{array}{l}\text { Trade \& } \\
\text { services }\end{array}$} \\
\hline \multicolumn{2}{|c|}{ Suburban/rural } & $\begin{array}{l}-0.23^{* * *} \\
(0.03)\end{array}$ & & $\begin{array}{l}-0.25^{* * *} \\
(0.04)\end{array}$ & \multicolumn{2}{|l|}{$\begin{array}{l}-0.11^{* * *} \\
(0.03)\end{array}$} \\
\hline \multicolumn{2}{|l|}{ Urban } & $\begin{array}{c}-0.01 \\
(0.03)\end{array}$ & & $\begin{array}{l}-0.26^{* * *} \\
(0.03)\end{array}$ & \multicolumn{2}{|l|}{$\begin{array}{c}-0.02 \\
(0.03)\end{array}$} \\
\hline \multicolumn{2}{|c|}{ Paris urban } & $\begin{array}{l}-0.02 \\
(0.03)\end{array}$ & & $\begin{array}{l}-0.24^{* * *} \\
(0.03)\end{array}$ & \multicolumn{2}{|l|}{$\begin{array}{l}-0.10^{* * *} \\
(0.03)\end{array}$} \\
\hline \multicolumn{2}{|c|}{ Paris metropolitan } & $\begin{array}{l}-0.15^{* * *} \\
(0.03)\end{array}$ & & $\begin{array}{l}-0.31^{* * *} \\
(0.04)\end{array}$ & \multicolumn{2}{|l|}{$\begin{array}{l}-0.28^{* * *} \\
(0.05)\end{array}$} \\
\hline
\end{tabular}

Source: CCFA, authors' calculations. Equation 4 is estimated by GMM separately for each type of purchasers. Other controlling variables include horsepower, brand fixed effects, segment fixed effects, class of $\mathrm{CO}_{2}$, month-year effects, and price (/10,000 euros). Instrumental variables for prices correspond to the price indices of iron (current and lagged value) and indices of export prices of tires, interacted with the car's weight; instrumental variables for intra-segment and intra-model market shares further include BLP-style instruments and differences of characteristics between gasoline and diesel versions. 